\title{
The advancements of gene editing and potential application to hereditary cancer
}

\author{
Zi Ying Tan1,2, Taosheng Huang ${ }^{3}$ and Joanne Ngeow ${ }^{1,2,4,5}$ \\ 'Lee Kong Chian School of Medicine, Nanyang Technological University, Singapore \\ 2Institute of Molecular and Cell Biology, Singapore \\ 3Division of Human Genetics, Cincinnati Children's Hospital Medical Center, Cincinnati, Ohio, USA \\ ${ }^{4}$ Cancer Genetics Service, Division of Medical Oncology, National Cancer Centre Singapore, Singapore \\ ${ }^{5}$ Oncology Academic Clinical Program, Duke-NUS Medical School Singapore, Singapore
}

Correspondence should be addressed to J Ngeow: Joanne.Ngeow.Y.Y@singhealth.com.sg

This paper is part of a thematic review section celebrating 65 Years of the Double Helix. The guest editors for this section were Charis Eng, William Foulkes and Jérôme Bertherat.

\begin{abstract}
Hereditary cancer predisposition syndromes are associated with germline mutations that lead to increased vulnerability for an individual to develop cancers. Such germline mutations in tumour suppressor genes, oncogenes and genes encoding for proteins essential in DNA repair pathways and cell cycle control can cause overall chromosomal instability in the genome and increase risk in developing cancers. Gene correction of these germline mutations to restore normal protein functions is anticipated as a new therapeutic option. This can be achieved through disruption of gain-of-function pathogenic mutation, restoration of loss-of-function mutation, addition of a transgene essential for cell function and single nucleotide changes. Genome editing tools are applicable to precise gene correction. Development of genome editing tools comes in two waves. The first wave focuses on improving targeting specificity and editing efficiency of nucleases, and the second wave of gene editing draws on innovative engineering of fusion proteins combining deactivated nucleases and other enzymes that are able to create limitless functional molecular tools. This gene editing advancement is going to impact medicine, particularly in hereditary cancers. In this review, we discuss the application of gene editing as an early intervention and possible treatment for hereditary cancers, by highlighting a selection of highly penetrant cancer syndromes as examples of how this may be achieved in clinical practice.
\end{abstract}
Key Words
- CRISPR-Cas
- gene correction
- germline mutation
- human genetics
- precision medicine

\section{Introduction}

Hereditary cancers are due to inheritance of cancer predisposition genes in which germline mutations are associated with increased cancer risks (Garber \& Offit 2005). Mutations can be in the form of (i) large genomic deletions encompassing all or most of protein function,

(ii) frameshift mutations and (iii) point mutations which introduce stop codon (nonsense) or amino acid substitution (missense). Pathogenic germline mutations can be broadly classified as loss-of-function or gainof-function mutations which are disease-causing or 
disease-associated, in adherence to American College of Medical Genetics standards and guidelines (Richards et al. 2015). Decades' worth of clinical, epidemiological and functional studies have established genotype-phenotype association of cancer predisposition genes and the key pathways they control (Vogelstein \& Kinzler 2004, Hodgson 2008, Rahman 2014). Such key pathways are signalling cascade-controlling cell proliferation, DNA damage and DNA-mismatch repair pathway, cell cycle checkpoint, apoptosis and cell survival. For patients who have been diagnosed with hereditary cancers, current treatment options include surgery, radiation, chemotherapy and gene therapy. Despite the strides made and successes achieved in cancer treatments, patients with hereditary cancers and other genetic disorders are looking primarily for measures that can mitigate their increased risk and prevent cancer initiation. This is an area whereby there has been limited success, and emerging genome editing strategies may provide the possibility of precision medicine based on targeted gene correction.

\section{Genome editing toolbox}

The fundamental concept of the gene editing field is that targeted DNA double-strand breaks (DSBs) in mammalian cells could be used to stimulate endogenous DNA repair machinery. Two major repair pathways are either homology-directed repair (HDR) or non-homologous end joining (NHEJ) (Capecchi 1989, Takata et al. 1998). HDR is dependent on a repair template with ends homologous to the break site, whereas NHEJ functions to repair without a template, and is therefore error prone and often ends up with insertions and/or deletions (indels) at the break site. HDR is useful in targeted gene editing, whereas NHEJ is used in targeted mutagenesis to generate functional knockout. The molecular scissors that recognize and cut DNA are categorized into zinc finger nucleases (ZFNs), transcription activator-like effector nucleases (TALENs) and clustered regularly interspaced short palindromic repeat (CRISPR)-associated (Cas) system, which are able to recognize specific DNA/RNA sequences via protein-DNA or RNA-DNA interactions and cleave DNA. The detailed comparison of ZFNs, TALENs and CRISPR-Cas has been reviewed extensively (Doudna 2014, Chira et al. 2017, Guha et al. 2017).

\section{ZFNs and TALENs}

ZFNs and TALENs are hybrid proteins, which contain DNAbinding domains tethered to DNA cleavage restriction enzyme FokI (Li et al. 2011) (Fig. 1A and B). Both classes of protein are dimeric in nature, thus requiring design of two independent DNA-binding domains to target a single sequence. Specificity of ZFNs depends on forward and reverse strand sequences conferred by left and right zinc finger DNA-binding modules, respectively, plus a linker between these two DNA-binding arrays and FokI catalytic domain that can induce HDR (Kim et al. 1996, Miller et al. 2007). ZFNickase is engineered via inactivation of one monomer in a ZFN dimer, thus improving HDR by reducing unwanted mutagenesis from NHEJ (Ramirez et al. 2012). In contrast, TALENs work in a more sophisticated way - for each 33-39 amino acid repeat positions 12 and 13 , determine the target specificity and follow the rules. The rules are: HD binds to $\mathrm{C}$, NK or NN binds to G, NI binds to A and NG binds to T (Boch et al. 2009, Miller et al. 2011).

\section{CRISPR-Cas}

Compared to the ZFN and TALEN systems, the CRISPRCas gene editing platform is less time consuming, yet highly affordable. Since the initial identification of bacterial CRISPR array in Escherichia coli (Ishino et al. 1987), Cas9 isolated from Streptococcus pyogenes was later discovered to be able to cleave DNA when guided by RNA (Jinek et al. 2012). The application of class 2 type II CRISPR-Cas9 (Makarova et al. 2017) has evolved exponentially from bacterial immune system surveillance to mammalian genome editing toolbox especially within the last 5 years (Hsu et al. 2014, Lander 2016). The principle of CRISPR lies in two components: a Cas9 protein and a $20 \mathrm{bp}$ single-guide RNA (sgRNA), which refers to a synthetic fusion of naturally occurring bacterial CRISPR RNA (crRNA) and trans-activating crRNA (Jinek et al. 2012). sgRNA directs the Cas9 protein to its target, with the latter introducing DSBs. Target sites must reside next to and $5^{\prime}$ of a protospacer adjacent motif (PAM) sequence that matches $5^{\prime}$-NGG-3'. Therefore, target site recognition can be programmed by designing the $5^{\prime}$ end of the sgRNA. Crystal structure of Cas9-sgRNA-DNA ternary complex showed that Cas9 consists of two lobes, a recognition (REC) lobe and a nuclease (NUC) lobe, which create a positively charged groove at their interface, to accommodate sgRNA:DNA heteroduplex (Nishimasu et al. 2014). The formation of a DNA-RNA heteroduplex based on base-pairing interaction at a specific recognition site necessitates the complementary binding by the REC lobe and cleavage by Cas9-sgRNA complex by the NUC lobe. Upon conformational change, the target DNA strand 
is cleaved by one of the Cas9 nuclease domains $\mathrm{HNH}$, whereas the non-target strand is cut by the RuVC domain, resulting in blunt-end DSBs (Fig. 1C) (Sternberg et al. 2015, Jiang \& Doudna 2017).

Instead of DSBs, Cas9 nuclease can also be transformed to single-strand DNA Cas9 nickase (Cas9n) via inactivation of one of the two nuclease domains from the NUC lobe. D10A mutation on RuVC domain, or H840A or N863A mutation on $\mathrm{HNH}$ domain, renders Cas9n cuts either complementary or non-complementary DNA target strands, thereby improving specificity and increasing HDR repair (Fig. 1D) (Jinek et al. 2012, Gasiunas et al. 2012, Cong et al. 2013, Nishimasu et al. 2014). Co-localization of paired Cas9n can be targeted to sites on opposite strands (guided by distinct sgRNA-Cas9 complexes) separated by $4-100 \mathrm{bp}$, so that both indel mutations via the NHEJ mechanism and HDR repair can be generated through double nicking with improved specificity (Mali et al. 2013, Ran et al. 2013). However, being an active monomer and the addition of a second sgRNA, paired Cas9n system may able to cleave off-target genomic sites and introduce new point mutations (Mali et al. 2013, Ran et al. 2013). To circumvent this limitation, fusion of an active non-specific FokI endonuclease cleaving domain to a catalytically dead Cas9 (dCas9) domain - which contains both D10A and H840A mutations in its nuclease - would ensure that the fusion protein cleaves only when two simultaneous distinct Cas9-sgRNA complexes bind to adjacent sites (Fig. 1E) (Guilinger et al. 2014, Tsai et al. 2014). This provides an increased specificity ( 4-fold higher), since the chance of dimers causing offtarget binding event is lower than the chance of Cas9n monomer off-target binding events (Guilinger et al. 2014).

As hereditary cancers can be associated with more than one genetic mutation known to increase cancer risk, targeting and editing multiple genomic sites in one step may be more desirable in these cases in order to save time and cost. This requires stacking of multiple sgRNA cassettes into one plasmid or delivery of multiple constructs, which could be tedious (Cong et al. 2013, Xie et al. 2015). The latest reports show that multiplex gene editing for up to four genes in mammalian cells and three genes in mouse brain is feasible by using a single-customized CRISPR-Cpf1 crRNA array (Zetsche et al. 2016). This is because Cpf1 (also known as Cas12a) is smaller than Cas9 and target recognition relies on only a single but shorter crRNA strand (Zetsche et al. 2015).

In addition to various Cas9 protein modifications, altering the length of the DNA:sgRNA length interface seems to influence on-target specificity of CRISPR-Cas9.
A

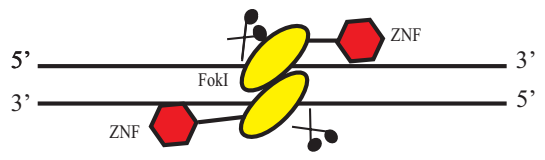

B

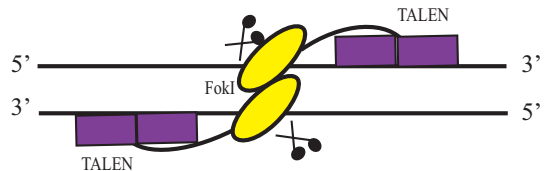

C

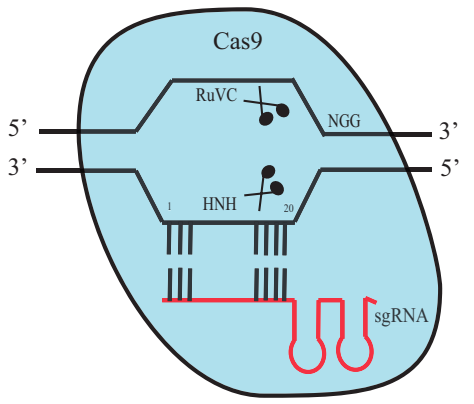

D

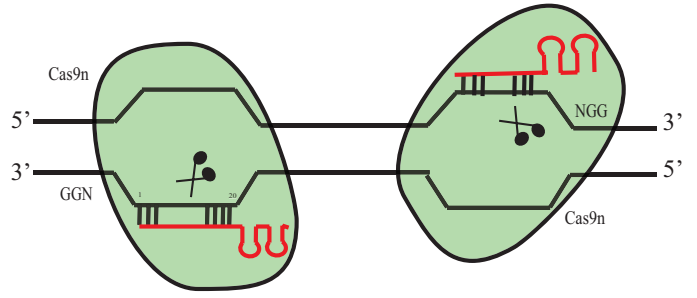

$\mathbf{E}$

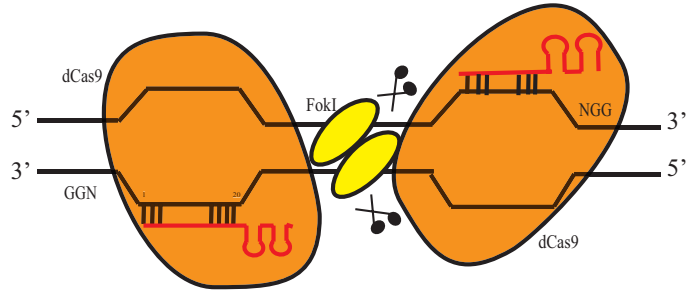

Figure 1

Genome editing toolbox. (A) ZFNs and (B) TALENs are customized DNA-binding domains fused to non-specific Fokl endonuclease, which must dimerize to cut the target DNA. (C) CRISPR-Cas9 is an RNA-guided endonuclease that uses sgRNA:DNA base pairing to mediate binding of Cas9 to target sequence. Cas9 cleaves complementary strand with its $\mathrm{HNH}$ domain, and cleaves non-complementary strand via RuVC domain, generating a DSB. DNA recognition relies on a PAM sequence (NGG) immediately next to target region complementary to sgRNA. (D) A Cas9n is generated by inactivating nuclease catalytic site in either HNH or RuVC domain, thereby causing single-strand break ('nick'). A paired Cas9n can be targeted by two distinct sgRNAs to improve target specificity. (E) Catalytically dCas 9 is another engineered variant, which is defective in DNA cleavage, but retains target recognition and binding ability. It can be fused to non-specific Fokl endonuclease so that target site cleavage can only occur when Fokl is dimerized, hence increasing target specificity. Cas9n, Cas9 nickase; CRISPR, clustered regularly interspaced short palindromic repeat; dCas9, dead Cas9; DSBs, double-strand breaks; PAM, protospacer adjacent motif; sgRNA, single-guide RNA; TALENs, transcription activator-like effector nucleases; ZFNs, zinc finger nucleases.
2018 Society for Endocrinology Published by Bioscientifica Ltd. Printed in Great Britain 
Truncated gRNA ( $<20 \mathrm{bp}$ ) is shown to decrease unwanted mutagenesis at off-target sites by as much as 5000 -fold or more via abrogation of indel formation, with not abrogation of 'functional binding' (Fu et al. 2014, Dahlman et al. 2015). Coupled with double Cas9n, truncated gRNA can lead to further reduction of off-target effects. This is in contrast to the target effect from lengthening the $5^{\prime}$ end of the complementary region, which results in reduction of on-target editing efficiency (Ran et al. 2013, Cho et al. 2014).

Apart from DNA as the substrate of Cas9, nuclearlocalized RNA-targeting CRISPR-Cas9 (RCas9) enabled recognition of endogenous mRNA (O'Connell et al. 2014, Nelles et al. 2015, 2016). This is based on a mismatch PAM sequence in the PAMmer/RNA hybrid with singlestrand RNA (ssRNA) that allows exclusive cleavage of ssRNA in the presence of non-PAM target double-strand DNA (O'Connell et al. 2014, Nelles et al. 2015). Further development of RCas9 showed that it can support specific targeting and eliminate microsatellite repetitive RNAs such as CUG and CCUG, CAG and GGGGCC, which are toxic RNA species accumulated in nuclear foci responsible for inherited neurological disorders Huntington's disease, myotonic dystrophy and amyotrophic lateral sclerosis (Batra et al. 2017). Notably, RCas9 targeting reversed disease phenotypes such as reduced polyglutamine protein, relocated repeat-bound proteins similar to healthy cells, eliminated RNA loci and efficiently reversed myotrophic-related splicing in patient myotubes, suggesting the potential of RCas9 in human therapeutic applications (Batra et al. 2017).

\section{CRISPR 2.0}

Repurposing CRISPR-Cas9 has continuously expanded the repertoire of the genome editing toolbox. This is largely based on the exploitation of a dCas9. Given its precise target recognition and binding without DSBs, dCas9 can be fused to various enzymes for different purposes. For example, fusing dCas9 with nucleoside deaminases for direct irreversible nucleotide modification (Komor et al. 2017a), fusing dCas9 with fluorescent reporter for tracking and imaging (Nelles et al. 2016), and fusing dCas9 with transcriptional activators to mediate gene expression (Liao et al. 2017, Zhou et al. 2018) and even nuclear reprogramming (Liu et al. 2018).

Unlike programmable nucleases which introduce small fragment of transgene or indels by NHEJ at the target site, programmable nucleoside deaminases enable nucleotide substitution or by converting $\mathrm{C}$ to $\mathrm{T}$ (or $\mathrm{G}$ to
A to a lesser extent) without DSBs (Komor et al. 2017b). The technique, called base editing (BE), can be achieved through fusion of dCas9 to APOBEC, a cytidine deaminase able to induce cytosine to uracil conversion, without DNA cleavage (Fig. 2A) (Komor et al. 2016, Nishida et al. 2016, Yang et al. 2016). This technique was tested in somatic cell nuclear transfer cloned human embryo - derived from immature oocytes and beta thalassemia patients' skin and blood cells - and was able to correct HBB-28 (A $>$ G) point mutation at over $20 \%$ repairing efficiency (Liang et al. 2017). The fourth generation of BE (BE4) is now being tested to increase efficiency of C:G to A:T BE by approximately $50 \%$ while halving the frequency of offtarget compared to BE3 (Komor et al. 2017a). Interestingly, Cas9-hypothetical adenine base editor (ABE) has been reported to mediate conversion of A:T to C:G base pairing in genomic DNA without DSBs (Gaudelli et al. 2017) (Fig. 2B). In this massive effort to evolve tRNA adenine deaminase (TadA) for seven generations in bacteria, subclasses of a novel TadA protein variant (ABE1-ABE7) fused to CRISPR-Cas9 are found to be capable of editing all four transitions (C to T, A to $G, T$ to $C$ and $G$ to $A$ ) (Gaudelli et al. 2017). This exciting discovery expedites the goal to edit human genetic diseases due to point mutation or single nucleotide polymorphism, as demonstrated by the successful conversion of point mutation that causes hereditary hemochromatosis in lymphoblastic cell line (Gaudelli et al. 2017).

Distinct from RNA-guided DNA-targeting CRISPR effectors such as Cas9 and Cpf1, a new variant type VI CRISPR-associated RNA-guided RNA-targeting effector Cas13 (previously known as C2c2) has been discovered to recognize RNA and is specialized to the RNA interference (Abudayyeh et al. 2016, East-Seletsky et al. 2016, Shmakov et al. 2017). In contrast to Cas9 which cleaves DNA, Cas13a enzyme lacks a DNase domain and cleaves RNA with its higher eukaryotes and prokaryotes nucleotidebinding (HEPN) endoRNase domain, which is commonly associated with ribonucleases (Fig. 2C) (Liu et al. 2017). The crRNA-target RNA duplex binds in a positively charged central channel of the nuclease lobe, leading to conformational change of the Cas13a protein. This in turn triggers activation of the HEPN catalytic site of Cas13a and subsequently cleavage of both the ssRNA target and collateral RNAs (Liu et al. 2017). Interestingly, it has been shown that two orthogonal Cas13a subfamilies LbuCas13a and LbaCas13a cleave ssRNA preferentially at uridines and adenosines, respectively (East-Seletsky et al. 2017). Importantly, Cas13a from Leptotrichia wadei (LwaCas13a) has been shown to knockdown RNA as effectively as RNA 
A

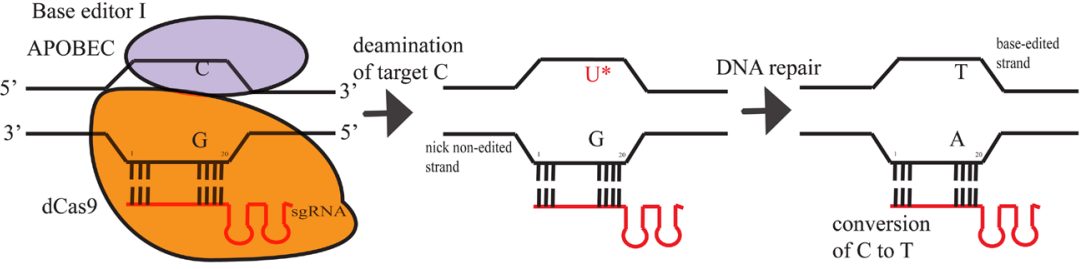

B Base editor II

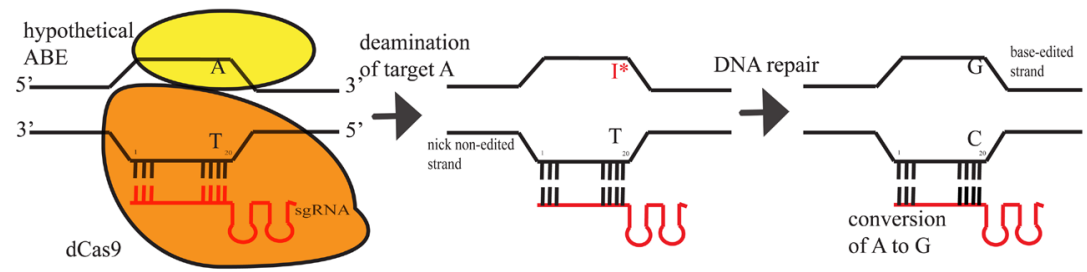

C

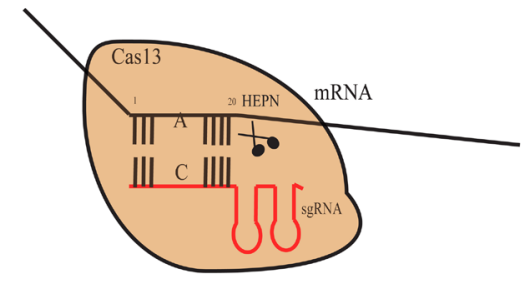

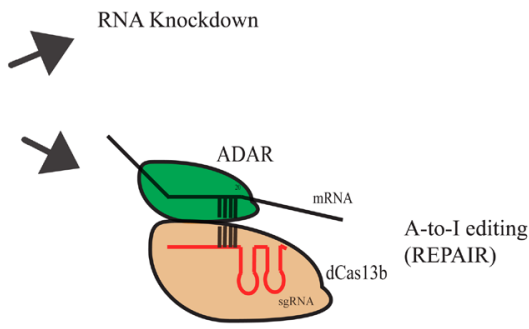

\section{Figure 2}

CRISPR 2.0. Base editor I is a fusion protein of dCas9 and APOBEC (A), whereas II is a hypothetical $A B E$ evolved from tRNA adenosine deaminase (B) that catalyses conversion of $C>T$ or $A>G$, respectively, without generating DSBs. (C) Cas13 is a RNA-guided RNase that cleaves target single-strand RNA with HEPN domain, resulting in RNA knockdown. Fusion of dCas 13b to ADAR enzyme catalyses A-to-I RNA editing (REPAIR). ABE, adenine base editor; CRISPR, clustered regularly interspaced short palindromic repeat; DSBs, double-strand breaks; HEPN, higher eukaryotes and prokaryotes nucleotide-binding domain. interference, but with improved specificity (Abudayyeh et al. 2017). This establishes CRISPR-Cas13a as a flexible platform for RNA manipulation - viral RNA detector 'SHERLOCK' (Gootenberg et al. 2017), transcript tracking and knockdown, and makes it an attractive starting route to expand tools for RNA perturbations and binding.

Like Cas13a, subtype Cas13b proteins - isolated from Prevotella $s p$. - have collateral RNase activity that is activated by target recognition (Shmakov et al. 2017, Smargon et al. 2017). Analogous to Cas9 BE principle, catalytic inactive dCas13b - mutated at two histidine to alanine sites on HEPN domain H133A/H1058A - can revert two disease-associated G-to-A mutations when it is fused with a catalytic domain of A-to-I editing ADAR2 (Fig. 2C) (Cox et al. 2017). The proof-of-concept studies achieved 35\% G-to-A correction of $878 \mathrm{G}>\mathrm{A}$ (AVPR2 W293X) in X-linked nephrogenic diabetes insipidus and $23 \%$ correction of $1517 \mathrm{G}>\mathrm{A}$ (FANCC W506X) in fanconi anaemia (FA) (Cox et al. 2017). This dCas13b-ADAR2 system is referred to as RNA editing for programmable A-to-I replacement (REPAIR), which is engineered to edit full-length transcripts containing pathogenic mutations (Cox et al. 2017). Use of CRISPR-Cas in RNA-target knockdown or RNA editing is especially beneficial in fixing genetic mutations without causing permanent
DNA changes to the genome, as compared to CRISPRCas9 counterpart. More importantly, it bypasses ethical issues as it is considered 'safer' for genetic manipulation in living cells without leaving a trace. It is also suitable for transient but rapid alteration to transcript in less actively dividing cells such as neurons and muscle cells.

These data demonstrated that collective power from rationalized bioinformatics/phylogenetic classification, biochemical/structural studies, molecular engineering and functional experiments of CRISPR proteins has revealed more functionally useful proteins and guided scientists in extending innovative applications of CRISPR-Cas genome editing toolbox (Nakade et al. 2017, Shmakov et al. 2017).

\section{Towards realization of gene editing as potential application in hereditary cancers in the clinic}

CRISPR-Cas9 has been rapidly implicated in numerous studies to modify target genes in a variety of human diseases, both in mouse model and human cell lines, as has been reviewed extensively (Sander \& Joung 2014, Cai et al. 2016, Chira et al. 2017). Depending on the nature of disease-causing mutations that predispose carriers to cancer development, there are various ways to perform 
specific types of gene editing (Fig. 3). For a gain-of-function germline mutation, the pathogenic function of this protein can be inactivated either via indel formations by NHEJ-mediated gene editing or RNA knockdown by RNAtargeting Cas 13 protein (Fig. 3A), so that the constitutively activated mutant oncogene can be silenced. Nonsense mutations that lead to loss-of-function protein can be rescued through HDR-mediated repair, thus restoring normal function (Fig. 3B). Missense mutation of a single base pair can be corrected via the BE mechanism through the addition of four possible nucleotide transitions (Fig. 3C). Precise correction of nonsense and missense mutation via targeted gene editing can restore the normal protein level, activity and function of mutated tumour suppressor and oncogenes, subsequently maintaining normal cell proliferation through downstream signalling pathways. At the RNA level, REPAIR can be used to correct $\mathrm{G}>\mathrm{A}$ mutation (Fig. 3D) without genome modification (Cox et al. 2017).

\section{Mechanisms behind hereditary cancer predisposition}

Hereditary cancers are due to inheritance of cancer predisposition in which germline mutations confer increased risks of cancer (Garber \& Offit 2005, Hodgson 2008, Rahman 2014). Averagely $10 \%$ of all cancers are caused by inherited mutations, as opposed to de novo mutations. The germline mutations cause defects in
A

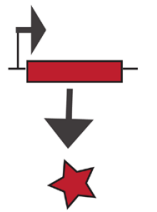

gain-of-function pathogenic protein
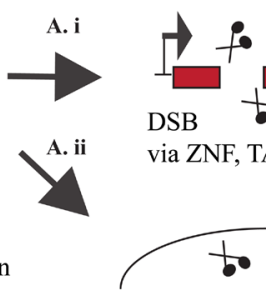

RNA targeting

CRISPR-Cas 13
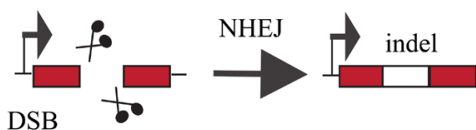

Truncated

nonfunctional

protein

via ZNF, TALENS, CRISPR-Cas9

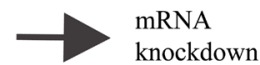

knockdown

\section{B insertion/ deletion of small/ large \\ genomic sequence; nonsense mutation

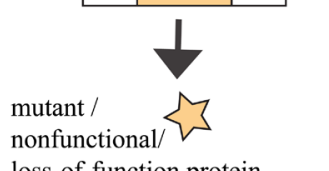 \\ loss-of-function protein}

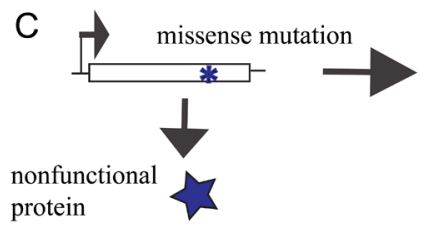

D

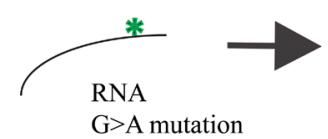

$\mathrm{G}>\mathrm{A}$ mutation

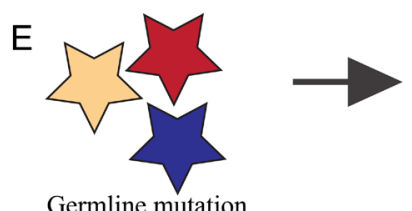

Germline mutation in carriers that could predispose to hereditary cancer syndrome

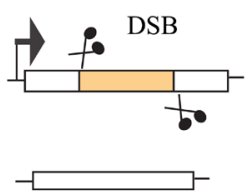

+ corrective HDR template
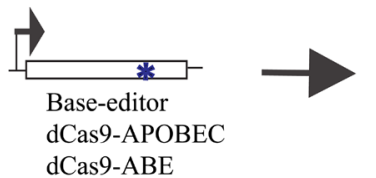

Corrected base sequence Functional protein dCas9-ABE

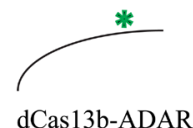

A-to-I

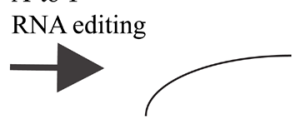

Corrected RNA
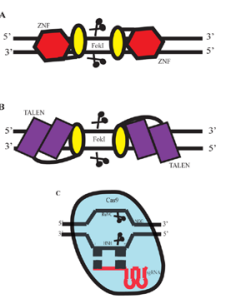

Gene editing tools

HDR

Functional

protein
Figure 3

Towards therapeutic gene editing applications in inherited cancers. (A) Inactivation of pathogenic mutation can be achieved either by (i) NHEJmediated indel formation on the targeted locus or (ii) RNA targeting by CRIPSR-Cas 13 to knockdown RNA. (B) Loss-of-function mutation caused by indel and nonsense mutations can be repaired through HDR-mediated pathway after DSB is generated. (C) Missense mutations can be corrected by base editor methods dCas9-APOBEC and dCas9-ABE, in which all four transitions ( $C$ to $T$, $A$ to $G, T$ to $C$ and $G$ to $A$ ) are possible. (D) REPAIR by dCas13b-ADAR2 can edit $G>A$ mutation post-transcriptionally without genome modification. (E) Pathogenic germline mutations can be corrected by various gene editing tools in order to stop germline transmission of diseasecausing mutations and eliminate risks of developing inherited cancers. $A B E$, adenine base editor; CRISPR, clustered regularly interspaced short palindromic repeat; DSBs, double-strand breaks; HDR, homology-directed repair; NHEJ, non-homologous end joining; REPAIR, RNA editing for programmable A-to-I replacement; TALENs, transcription activator-like effector nucleases; ZFNs, zinc finger nucleases. 
particular biochemical or molecular pathways that lead to genome instability and subsequently uncontrolled cell growth which promote tumour development (Table 1). Hereditary cancers can be broadly categorized into groups according to the key pathways, which are disrupted due to heritable germline mutations. Mutations in genes encoding for proteins involved in DNA repair damage pathway are accounted for numerous familial clustering of cancers, such as BRCA1/2 in hereditary breast and ovarian cancer, FA-complementation group in FA, mismatch repair genes in Lynch syndrome, and so on. Loss of DNA repair fidelity in patients harbouring this group of germline mutations leads to increased mutational burden and subsequently higher risk of cancer growth at young age. Genes controlling cell cycle is another major pathway contributing to hereditary cancers. For example, tumour suppressors TP53, PTEN, NF1 and APC are major players in P53, PI3K/Akt/mTOR, Ras/MAPK and $\beta$-catenin/WNT signalling pathways, respectively. Abnormal cell division occurs due to uncontrolled signalling pathways caused by loss of function of these mutated proteins. Contrary to these, gain-of-function oncogenes, such as RET and $M E T$ in multiple endocrine neoplasia type 2 (MEN2) and hereditary papillary renal carcinoma, result in constitutive activated tyrosine kinase pathway, causing cancerous growth. Correcting mutations in these target genes can rebuild functional proteins and the molecular pathways affecting genome stability and cell cycle, thus restoring cellular homeostasis.

\section{Gene editing of cancer predisposition genes}

Most of the patients inheriting pathogenic variants of cancer predisposition genes develop early-onset cancers, often at young age. Ideally, gene editing should prevent or reduce risk of early-onset cancers in children with germline mutation inheritance, rather than being offered as cancer treatment option when tumours have already been developed. Hence, the earlier the patients receive gene editing therapeutics, the better prognosis outlook in lifetime cancer risks. Time points of early intervention via gene editing to prevent hereditary cancer initiation can be broadly categorized into three stages: embryo, prenatal, children and young adults (Fig. 4).

Osteogenesis imperfecta patients transplanted with allogenic foetal mesenchymal stem cells (fMSCs) prenatally and postnatally did not suffer from new skeletal damage for the remainder of pregnancy and during infancy, as compared to a patient with similar COL1A2 genetic defect who was not transplanted and did not die at 5 months of age (Gotherstrom et al. 2014). Based on this clinical case report, prenatal cellular therapy via in utero fMSCs transplantation has potential in treating congenital disease before birth, without targeting COL1A2-mutated cells (Sagar et al. 2018). Moreover, transgenic epidermal stem cell cultures could generate an entire functional epidermis in a child with junctional epidermolysis bullosa, which is caused by inherited mutated laminin gene and often lethal due to chronic wounds and eventually skin cancer (Hirsch et al. 2017). These suggest that gene-corrected stem cells could repopulate in the young patients, infants and even in prenatal stage who are carrying inherited mutation, without necessarily targeting cancer cells. Successes from prenatal fMSCs transplantation and gene therapy to treat congenital diseases imply clinical feasibility in using geneedited stem cells, particularly induced pluripotent stem cells (iPSCs) from patients, as source for cellular therapy or engraftment for long-term repopulation. This would potentially treat hereditary cancers at individual level, but not for their next-generation offspring because it does not cause permanent genome modification.

\section{Gene editing without heritable genome modification}

It may not be that straightforward to carry out gene editing in one target cell types especially when one germline mutation increases risks in multiple types of cancers, for instance Li-Fraumeni and Lynch syndromes, as compared to hereditary gastric diffuse cancer when specific mutated CDH1 is known to affect stomach only. Delivery of gene editing vehicles into patients locally must be efficient to reach a certain threshold unit sufficient enough to transform target cells in vivo, which later repopulate in the body. Likewise, transplantation of gene-edited cells ex vivo must achieve substantial level of editing and harbour regeneration ability in order to engraft. Alternative approach is to engineer an inducible CRISPR-Cas9 cassette or inducible gRNA into adeno-associated viruses (AAVs) locus in zygotic genome, so that it can be activated for precise editing in a spatiotemporal manner through chemical induction and sgRNAs in later growth phase, in various context-dependent disease scenarios (Davis et al. 2015, de Solis et al. 2016, Liu et al. 2016).

For haematological oncology such as FA, current treatments include administration of androgen, hematopoietic growth factors and bone marrow transplant (Shukla et al. 2012, Ebens et al. 2017). Early study reports disease-corrected hematopoietic progenitors can be generated from FA-induced iPSCs using lentiviral transgenes gene therapy method (Raya et al. 2009). 

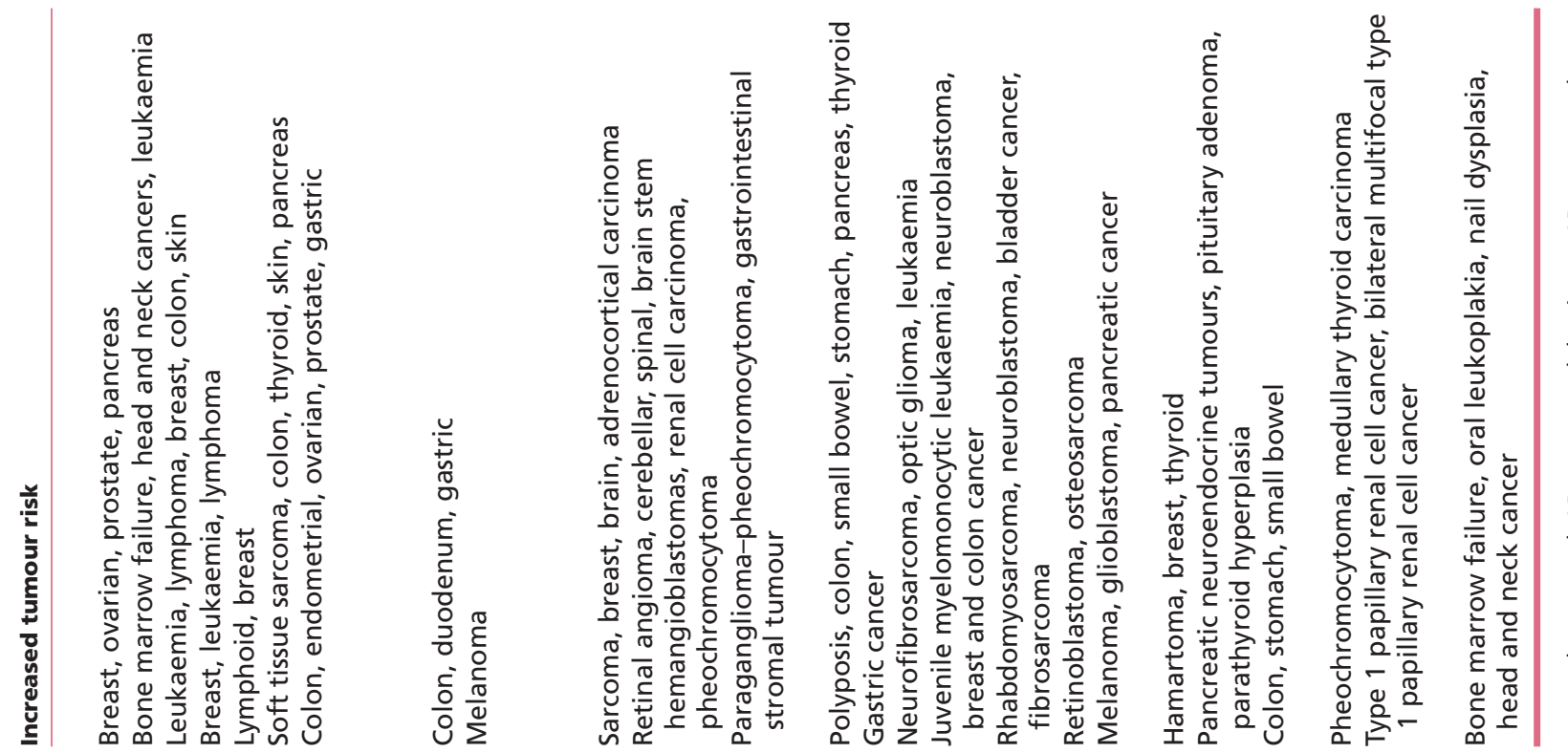

安是

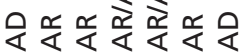

$\frac{0}{4} \frac{⿱ 乛}{4}$

还是

安安安安

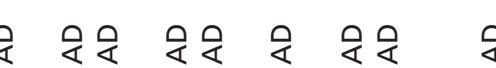
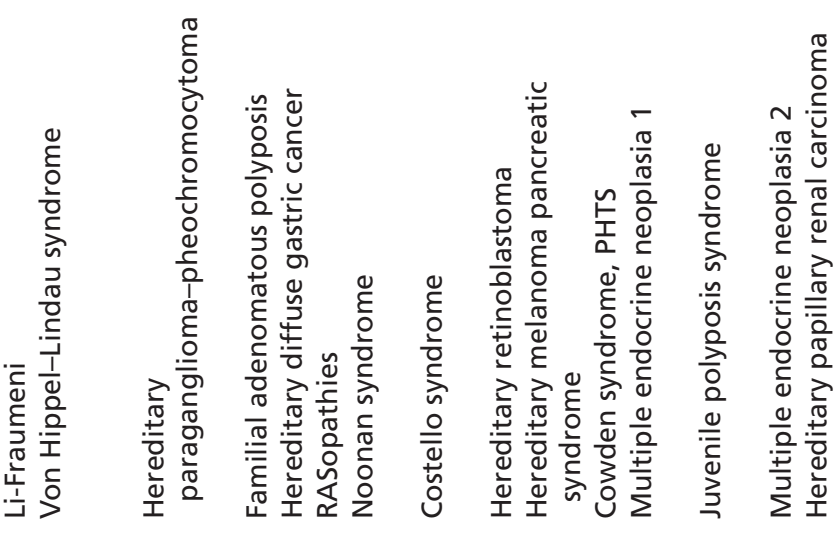

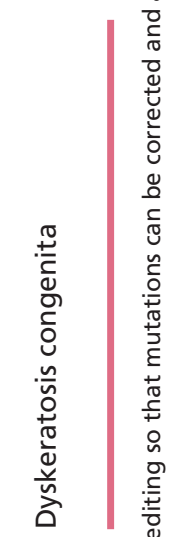

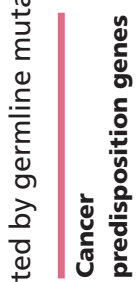

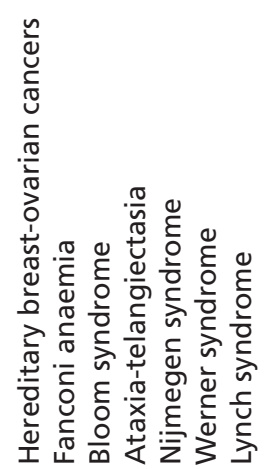

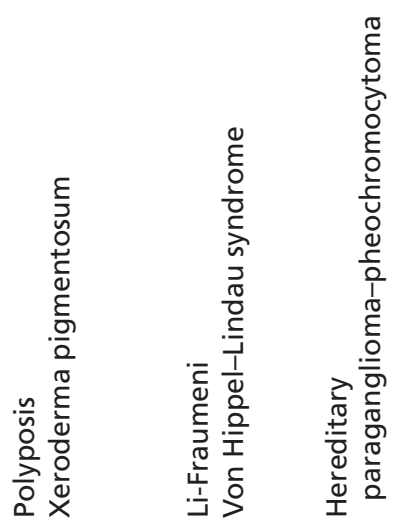

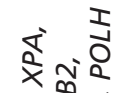 \\ ญัด เิ

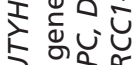

$\cong \stackrel{*}{\stackrel{4}{c} m}$

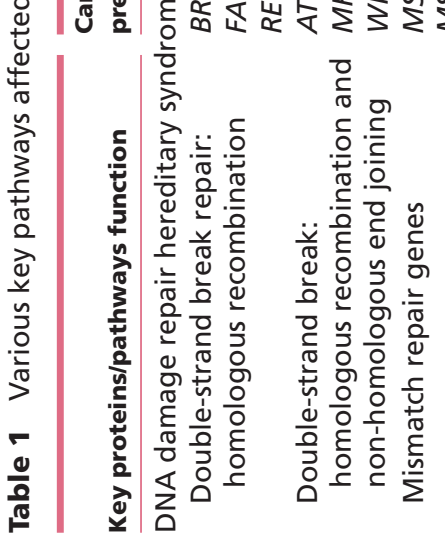

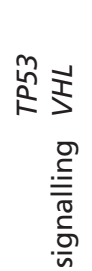

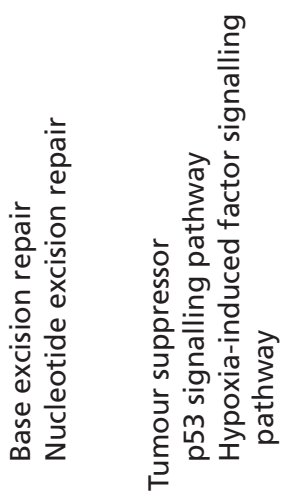

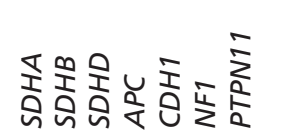

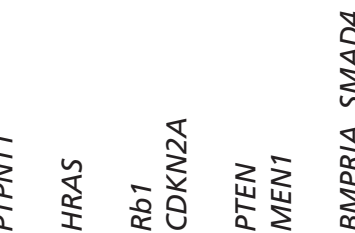

$\sum_{\substack{1 \\ 0}}^{+}$

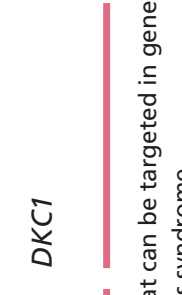
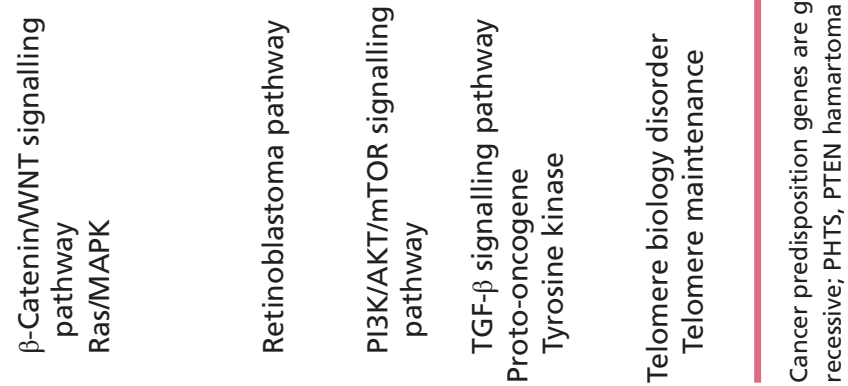
To date, two FANCA lentiviral gene transfer clinical trials are ongoing, one at Fred Hutchinson Cancer Research Center (NCT01331018), another one at Vall d'Hebron Research Institute (NCT02931071). Reports from clinical trial show that while safe integration of gene transfer cassette was well tolerated, the rapidly diminished number of transduced cells in the periphery remained the most challenging task (Adair et al. 2016a,b). To overcome this limitation, gene-corrected patient iPSCs-derived hematopoietic stem cells (HSCs) can be transplanted to FA patients (Navarro et al. 2016). The critical differences between allogenic HSCs and gene-corrected iPSCs are that the former method requires matched donors and immunosuppressant drugs. iPSCs are the ideal cell type for gene editing therapeutics due to their self-renewal property, differentiation potential, less immunogenicity and less aggressive than current treatment options such as chemotherapy and radiation. Numerous studies demonstrate successful editing of mutated FA genes such as FANCA, FANCC, FANCI, FANCD1 and FANCF by ZNF-mediated, helper-dependent adenoviral vector, lipid-cationic-mediated CRISPR-Cas9 BE and RNA-edit platforms (Liu et al. 2014a, Rio et al. 2014, Osborn et al. 2015, 2016, Cox et al. 2017, Komor et al. 2017a, Skvarova Kramarzova et al. 2017) (Table 2). Colony-forming unit potential of gene-corrected FA iPSCs is reasonably high at approximately $12 \%$ of CD34+CD43+ (Rio et al. 2014), suggesting reasonable fitness in HSC repopulation. Genecorrected FA iPSCs are proven to display phenotypic reversions such as restoration of normal FANCA protein expression level, FANCD2 monoubiquitination and being able to form FANCD2 nuclear foci, rescue of mitomycin C sensitivity and chromosomal instability (Liu et al. 2014a). However, another study reported that gene-corrected FA primary cells may be outcompeted by diseased cancerous cells or normal untreated cells, rendering the benefit of treatment low (Osborn et al. 2015). Clonal derivation of FA primary cells is not possible (Osborn et al. 2016). Therefore, long-term repopulating HSCs and progenitor cells differentiated from gene-corrected iPSCs (Sugimura et al. 2017) are the ideal cell types for transplantation in FA patients.

In glioblastoma and neuroblastoma, affected cells are heterogenous postmitotic cells, it is extremely

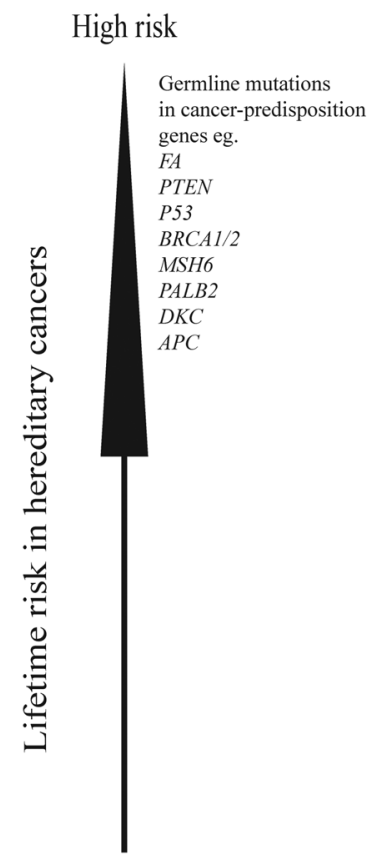

Low risk
Gene editing applications
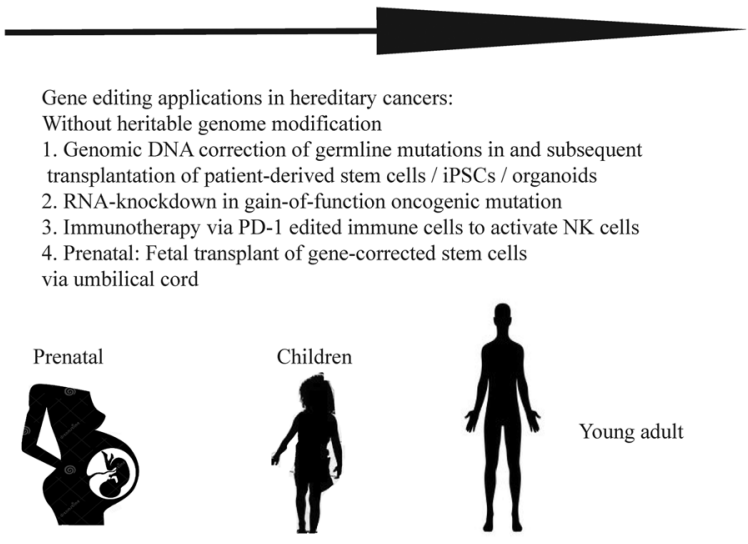

With heritable genome modification

5. Human germline editing

- Sperm/ oocytes

- Differentiated spermatogonia stem cells from parents' iPSC

- Corrected embryos

Young adult

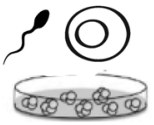

germ cells
patient-iPSC
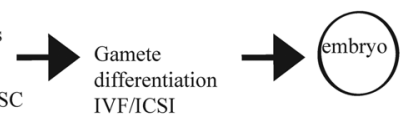

IVF/ICSI

\section{Figure 4}

Gene editing applications show great promises in correcting hereditary germline mutations as a medical intervention to prevent early development of hereditary cancers in patients. Stages where gene editing intervention can be introduced are (i) embryo/human germline; (ii) prenatal stage; (iii) children and young adults in order to lower lifetime hereditary cancer risk. Germline mutations can be corrected through multiple ways of gene editing with or without heritable genome modification in order to restore normal protein functions, either through human germline or gene-corrected patient-derived iPSCs and stem cells, knockdown RNA in gain-of-function oncogene expression, and immunotherapy via PD-1 to increase activated NK cells. iPSCs, induced pluripotent stem cells; NK, natural killer. 
Table 2 Examples of gene editing in various germline mutations associated with human inherited diseases.

\begin{tabular}{|c|c|c|c|c|c|}
\hline Inherited cancers & Mutations & Edited cells & Delivery method/agent & Editing method & Reference \\
\hline Cowden syndrome & $\begin{array}{l}\text { PTEN c.164+1_164+2insG } \\
\text { (42MGBA); c.125T>G L42R } \\
\text { (T98G) }\end{array}$ & $\begin{array}{l}\text { Glioblastoma } \\
\text { cell lines } \\
42 \mathrm{MGBA} \text { and } \\
\text { T98G }\end{array}$ & AAV-mediated & HDR & $\begin{array}{l}\text { Hill et al. } \\
\text { (2017) }\end{array}$ \\
\hline \multirow[t]{6}{*}{ Fanconi anaemia } & $\begin{array}{l}\text { FANCA c.710-5T }>C \text { and } \\
\text { C. } 3558 \text { ins }\end{array}$ & Patient iPSC & Lentiviral, AAVS1 locus & $\begin{array}{l}\text { ZFN-mediated } \\
\text { targeted } \\
\text { insertion; HDR }\end{array}$ & $\begin{array}{l}\text { Rio et al. } \\
\text { (2014) }\end{array}$ \\
\hline & FANCC c. $456+4 A>T$ & $\begin{array}{l}\text { Patient } \\
\text { fibroblast }\end{array}$ & Lipofectamine & CRISPR HDR & $\begin{array}{l}\text { Osborn et al. } \\
\text { (2015) }\end{array}$ \\
\hline & $\begin{array}{l}\text { FANCI c. } 1461 \mathrm{~T}>\mathrm{A} \text { and } \\
\text { C. } 3058+4 \mathrm{~A}>\mathrm{G}\end{array}$ & $\begin{array}{l}\text { Patient } \\
\text { fibroblast and } \\
\text { iPSC }\end{array}$ & AAV-puromycin plasmid & CRISPR HDR & $\begin{array}{l}\text { Osborn et al. } \\
(2016)\end{array}$ \\
\hline & FANCC c.1517 G>A W506X & HEK293FT & AAV & $\begin{array}{l}\text { RNA-edit by } \\
\text { ADAR }\end{array}$ & $\begin{array}{l}\text { Cox et al. } \\
\text { (2017) }\end{array}$ \\
\hline & $\begin{array}{l}\text { FANCD1 (886delGT and } \\
6162 \text { insT) }\end{array}$ & $\begin{array}{l}\text { Patient } \\
\text { fibroblast and } \\
\text { iPSC }\end{array}$ & Lipofectamine-plasmid & CRISPR HDR & $\begin{array}{l}\text { Skvarova } \\
\text { Kramarzova } \\
\text { et al. (2017) }\end{array}$ \\
\hline & FANCF & HEK293T cells & Lipofectamine-plasmid & $\begin{array}{l}\text { Base editing by } \\
\text { APOBEC }\end{array}$ & $\begin{array}{l}\text { Komor et al. } \\
(2017 a)\end{array}$ \\
\hline Tumour suppressor & p53 C>T (Tyr163Cys) & $\begin{array}{l}\text { Human breast } \\
\text { cancer } \\
\text { HCC1954 }\end{array}$ & Nucleofection & $\begin{array}{l}\text { Base editing by } \\
\text { APOBEC }\end{array}$ & $\begin{array}{l}\text { Komor et al. } \\
\text { (2016) }\end{array}$ \\
\hline $\begin{array}{l}\text { Hypertrophic } \\
\text { cardiomyopathy } \\
\text { (HCM) }\end{array}$ & $\begin{array}{l}\text { MYBPC3 } 4 \text { bp GAGT } \\
\text { deletion }\end{array}$ & $\begin{array}{l}\text { Sperm; human } \\
\text { zygote }\end{array}$ & AAV & HDR & $\begin{array}{l}\text { Ma et al. } \\
(2017)\end{array}$ \\
\hline$\beta$-thalassemia & $H B B-28$ A > G & $\begin{array}{l}\text { SCNT cloned } \\
\text { human }\end{array}$ & Lentiviral plasmid & $\begin{array}{l}\text { Base editing by } \\
\text { APOBEC }\end{array}$ & $\begin{array}{l}\text { Liang et al. } \\
\text { (2017) }\end{array}$ \\
\hline
\end{tabular}

AAVs, adeno-associated viruses; CRISPR, clustered regularly interspaced short palindromic repeat; HDR, homology-directed repair; iPSCs, induced pluripotent stem cells; SCNT, somatic cell nuclear transfer; ZFN, zinc finger nucleases.

challenging to edit non-dividing cells as CRISPR editing pathway requires DNA replication and cell division. As compared to current megatherapy offered to children with neuroblastoma, genetically corrected neural iPSCs may show great promise in treating inherited brain tumours. For example, PTEN correction in two glioblastoma multiforme (GBM) cell lines by AAV-mediated gene editing showed attenuated cellular proliferation (Hill et al. 2017), which was a desired outcome after restoration from hyperactivated PI3K/Akt/mTOR cell cycle pathway due to a mutated tumour suppressor gene PTEN. This implies that gene-corrected patient-derived glioma stem cells could potentially beneficial in brain cancer treatment.

Moreover, intestinal organoids have been transplanted to repair damaged colon, albeit at low engraftment success (Yui et al. 2012, Huch et al. 2013). Organoids are self-organizing stem cells in a diverse and complex multicellular tissue system. A proof-of-concept study showed gene-corrected organoids cultured from cystic fibrosis patients' intestinal stem cells can be achieved and expanded (Schwank et al. 2013). This combination of gene-edited stem cells 3D organoids derived from patients' adult stem cells is envisioned as autologous stem cell therapy for currently incurable hereditary diseases (Yin et al. 2016). This could be relevant to treating young adults with hereditary cancers such as Lynch syndromes, by incorporating gene-corrected intestinal organoids into young patients' colon after polyp removal to repair damage or intervene earlier to displace the polyp growth due to germline mutations.

In contrast, constitutively activated mutant oncogene can be inactivated either by indels by NHEJ-mediated gene editing or RNA knockdown. Hereditary lung cancer syndrome target never smokers with an estimated $31 \%$ risk with germline EGFR T790M mutation (Gazdar et al. 2014). Analysis of tumour DNA for EGFR exons 18-21 revealed an additional L858R mutation in exon 21 (Gazdar et al. 2014). L858R is a classical activating oncogene mutation accounting for $\sim 40 \%$ of all EGFR mutation. Targeted disruption of allele specific oncogene L858R by the CRISPR-Cas9 via adenovirus (Ad) has led to tumour growth inhibition in mouse lung cancer xenograft model (Koo et al. 2017). As highlighted, RNA knockdown by CRISPR can be applied routinely or daily course of targeted gene silencing; this may be potentially useful in silencing gain-of-function oncogene expression 
such as constitutively activated RET in MEN2, a dominant inherited cancer that affects neuroendocrine organs. RET knockdown by shRNA in medullary thyroid cancer derived cells increased cells' sensitivity to cisplatininduced apoptosis (Bagheri-Yarmand et al. 2015). This can be an alternative choice to achieve long-term silencing of oncogenes without DNA modification in patients who are inheriting these germline mutations.

Gene editing in immune cells to tackle hereditary cancers could potentially alter immune surveillance and influence the course of overall cancer treatment. For example, studies show that among children with FA, dyskeratosis congenita and Cowden syndrome patients, natural killer (NK) cells are significantly lower (Jyonouchi et al. 2011, Myers et al. 2011, Starink et al. 1986). Targeting $P D-1$ in mouse model of GBM shows that NK cells are increased and the tumour growth is slower in the treated group (Huang et al. 2015). This implies that targeting $P D-1$ via CRISPR could be potentially useful in activating NK cells differentiation and cytotoxic potential through T-cell-based therapy in patients with hereditary cancers. However, this application of gene editing does not aim to prevent transmission of germline mutations to offspring.

\section{Gene editing with heritable genome modification}

While editing the germline is the easiest and most powerful way to demonstrate gene editing's curative potential in inherited cancers, it is also the most embroiled in controversy (Doudna \& Sternberg 2017). Proof-of-concept studies have demonstrated that CRISPR-Cas9 gene editing in sperm and zygote resulted in successful correction of inherited disease-causing mutations. For instance, the $M Y B P C 3$ and $H B B$ genes accounted for hypertrophic cardiomyopathy and beta thalassemia, in early human embryonic developmental stage in vitro (Liang et al. 2017, Ma et al. 2017) (Table 2). In this study, they specifically targeted the $4 \mathrm{bp}$ GAGT deletion in the MYBPC3 gene in human embryos with a total targeting efficiency of $72.7 \%$, which is higher than $27.9 \%$ in iPSC lines. This suggests a more efficient delivery by zygote microinjection. DSBs in human gametes and zygotes were preferentially resolved using an endogenous HDR mechanism, using WT allele from the oocyte as the repair template, as they did not find any evidence of HDR using exogenous single-strand oligo donor (Ma et al. 2017).

Potential clinical routine for the hereditary cancer prevention via gene editing would most likely involve genetic testing, genetic counselling, preimplantation genetic diagnosis and prenatal testing. Options exist for couple who intend to reproduce when they know both of them are carriers of pathogenic mutation of hereditary cancer predisposition genes. Human germline editing is possible through editing either male or female germ cells, IVF or ICSI-produced embryos and differentiated gametes from patient-derived iPSCs (Fig. 4) (Vassena et al. 2016). In addition to common risk of embryo manipulation in vitro such as chromosomal instability, there are multiple risks associated with these germline or embryo gene editing steps (Ishii et al. 2017a). While there remain numerous uncertainties at the human embryo editing step, it is crucial to achieve balance between the opportunities of rescuing hereditary germline mutations of cancer predisposition genes and the risks of gene correction via CRISPR.

As of this writing, human germline gene editing therapy is limited to the in vitro research model (Evitt et al. 2015, ACMG Board of Directors 2017, Ormond et al. 2017, Howard et al. 2018). Clinical use of human germline gene editing is prohibited currently. It should proceed only if (1) safety and efficacy issues are resolved; (2) society has agreed on bounds; (3) appropriate oversight is in place; (4) justice and equity concerns are addressed and (5) it is transparent, as largely recommended by a total of 11 organizations, led by the American Society of Human Genetics (Table 3) (Ormond et al. 2017) (Supplementary Fig. 1, see section on supplementary data given at the end of this article). Detailed ethical, legal and social issues are being highlighted in Supplementary Fig. 1 for consideration before moving towards realization of a responsible gene editing in humans (Howard et al. 2018, de Wert et al. 2018). In the future, gene editing may also impact on genetic counsellors when it becomes an available option in the clinics (Capps et al. 2017).

\section{Challenges in translating gene editing from bench to bed}

The simplicity of short length sgRNA in guiding specificity in the whole genome has made the CRISPRCas9 system a popular choice, but at the same time, offtarget issues remain as the primary concern in therapeutic application (Fu et al. 2013, Pattanayak et al. 2013, Cho et al. 2014). Numerous online tools are available to assess the optimized sgRNA design based on customized queries, namely CRISPR design tool, CasFinder, E-Crisp, CCTop and ZiFiT targeter. Conversely, there are tools for off-target prediction such as CROP-IT and Cas-OFFinder. For therapeutic applications, off-target analysis must be carried out to assess nuclease dosage and delivery 
Table 3 ASHG human germline editing statement.

\begin{tabular}{|c|c|c|c|c|c|c|c|c|c|c|c|}
\hline Arguments & $\begin{array}{l}\text { The } \\
\text { Hinxton } \\
\text { group }\end{array}$ & $\begin{array}{l}\text { NAS, } \\
\text { NAM, } \\
\text { CAS and } \\
\text { UK RSIS }\end{array}$ & $\begin{array}{l}\text { NAS and NAM } \\
\text { committee on } \\
\text { human gene } \\
\text { editing }\end{array}$ & $\begin{array}{l}\text { ASGCT } \\
\text { and JSGT }\end{array}$ & ISSCR & $\begin{array}{l}\text { Baltimore } \\
\text { et al. (2015) }\end{array}$ & EGE & $\begin{array}{l}\text { Lanphier \& } \\
\text { Urnov (2015) }\end{array}$ & ACMG & NIH & HFEA \\
\hline $\begin{array}{l}\text { Basic research should be } \\
\text { conducted }\end{array}$ & $x$ & $x$ & $x$ & $x$ & $x$ & $x$ & & & & & $x$ \\
\hline $\begin{array}{l}\text { Preclinical research } \\
\text { should be conducted }\end{array}$ & & $x$ & $x$ & & & & & & & & \\
\hline $\begin{array}{l}\text { There should be a } \\
\text { partial or full } \\
\text { moratorium on } \\
\text { research }\end{array}$ & & & & & & & $x$ & $x$ & & $x$ & \\
\hline $\begin{array}{l}\text { Diverse stakeholders } \\
\text { should be involved in } \\
\text { decision-making }\end{array}$ & $x$ & $x$ & $x$ & $x$ & $x$ & $x$ & $x$ & $x$ & $x$ & & \\
\hline $\begin{array}{l}\text { Any public policies } \\
\text { regulating this area of } \\
\text { science should be } \\
\text { flexible }\end{array}$ & $x$ & & & & & & & & & & \\
\hline $\begin{array}{l}\text { Clinical use should not } \\
\text { proceed currently }\end{array}$ & $x$ & $x$ & $x$ & $x$ & $x$ & $x$ & $x$ & $x$ & $x$ & & \\
\hline $\begin{array}{l}\text { Clinical use should } \\
\text { proceed only if safety } \\
\text { and efficacy issues are } \\
\text { resolved }\end{array}$ & $x$ & $x$ & $x$ & $x$ & $x$ & $x$ & $x$ & & $x$ & & \\
\hline $\begin{array}{l}\text { Clinical use should } \\
\text { proceed only if society } \\
\text { has agreed on bounds }\end{array}$ & $x$ & $x$ & $x$ & $x$ & $x$ & & $x$ & & $x$ & & \\
\hline $\begin{array}{l}\text { Clinical use should } \\
\text { proceed only if } \\
\text { appropriate oversight } \\
\text { is in place }\end{array}$ & $x$ & $x$ & $x$ & & & & $x$ & & & & \\
\hline $\begin{array}{l}\text { Clinical use should } \\
\text { proceed only if justice } \\
\text { and equity concerns } \\
\text { are addressed }\end{array}$ & $x$ & & & $x$ & & & $x$ & & & & \\
\hline $\begin{array}{l}\text { Clinical use should } \\
\text { proceed only if it is } \\
\text { transparent }\end{array}$ & & & $x$ & & & $x$ & & & & & \\
\hline $\begin{array}{l}\text { Clinical use should be } \\
\text { discouraged } \\
\text { worldwide }\end{array}$ & & & & & & $x$ & & & & & \\
\hline
\end{tabular}

Reprinted from American Journal of Human Genetics, vol 101, Ormond KE, Mortlock DP, Scholes DT, Bombard Y, Brody LC, Faucett WA, Garrison NA, Hercher L, Isasi R, Middleton A, Musunuru K, Shriner D, Virani A \& Young CE, Human Germline Genome Editing, pages 167-176, Copyright (2017), with permission from Elsevier.

ACMG, American College of Medical Genetics; ASGCT, American Society for Gene and Cell Therapy; CAS, Chinese Academy of Sciences; EGE, European Group on Ethics in Science and New Technologies; HFEA, UK Human Fertilization and Embryology Authority; ISSCR, International Society for Stem Cell Research; JSGT, Japan Society of Gene Therapy; NAM, US National Academy of Medicine; NAS, US National Academy of Sciences; NIH, National Institutes of Health.

approach to ensure optimal conditions that produce the most favourable genomic surgery with high accuracy (Bolukbasi et al. 2015). In fact, it is particularly challenging to decide what is a 'tolerable' off-target activity from a genomic surgery (Tasan \& Zhao 2017). Several novel unbiased genome-wide off-target detection platforms have been built in cell-free assays or cell-based assays, as have been reviewed extensively (Zhang et al. 2015,
Tsai \& Joung 2016, Jung et al. 2017, Tasan \& Zhao 2017). A combination of both in vivo and in vitro analysis may be more comprehensive in identification of off-target sites, which can be affected by native chromatin structure and overall cell fitness effects due to certain mutations (Tasan \& Zhao 2017). However, it is still not clear that these measurements would be sufficient to prevalidate in vivo editing approaches. 
In addition, not every germline mutations can be targeted by $S$. pyogenes CRISPR-Cas9 system due to the absence of PAM sequence immediately near the target site. Therefore, more combinations of Cas9 variants from different prokaryotes that exhibit alternative non-canonical PAM sequences are continuously being discovered and engineered for a broader usage.

For a successful editing process, another challenge lies in effective delivery of gene editing tools to the target cell, and ensuring that they have sufficient half-lives for editing to take place before getting diluted out of cells (Yin et al. 2017). Delivery methods can be categorized into viral or non-viral. There are currently three types of viral delivery systems: retroviruses (lentiviral vector is the subclass), Ads and AAVs. AAVs are widely used in the gene therapy as they have the advantage of non-pathogenic, high transduction rate and stable expression in dividing and non-dividing cells (Daya \& Berns 2008). Compared to other virus vehicles, the limitation of AAVs is their $4.7 \mathrm{~kb}$ transgene size limit. Non-viral delivery system in gene transfer includes cell-penetrating particle (CPP) (Liu et al. 2016), cationic materials (like lipofectamine) and nanoparticles (Jin et al. 2009, Chen et al. 2016). In contrast, non-viral vectors are cheaper and easier to prepare, have no issue of insertional mutagenesis, allow for a limitless size for the transgene and are less immunogenic and oncogenic but tend to obtain lower expression of transgene. CPPmediated gene editing has been demonstrated to disrupt endogenous gene in human cell line via delivery of CRISPR-Cas9 complex (Ramakrishna et al. 2014, Suresh et al. 2017) and TALENs (Liu et al. 2014b). A recent study demonstrated a novel delivery vehicle called CRISPR-Gold - which is composed of gold nanoparticle conjugated to DNA plus cationic endosomal disruptive polymers could deliver Cas9 ribonucleoprotein complex and donor DNA into a wide variety of cell types, including immune cells, muscle cell progenitors, human iPSCs and human embryonic stem cells (Lee et al. 2017). The group also tested CRISPR-Gold in correcting DNA mutation that causes Duchenne muscular dystrophy in mice's legs via local injection, reporting that there is no toxic effect and minimal off-target effect observed (Lee et al. 2017). However, gold nanoparticle uptake into immune cells is known to activate pro-inflammatory cytokines, suggesting that this approach does have immunostimulatory properties (Dykman \& Khlebtsov 2017). Despite showing efficient delivery at low nanomolar protein concentration, this system ought to be optimized in terms of adjusting physiochemical parameters such as size, shape, electrical charge and surface functionalization for safety evaluation in preclinical development (Zuris et al. 2015).

Most recently, study reports presence of preexisting humoral and cell-mediated adaptive immune system of Cas9 in humans (Charlesworth et al. 2018). Abundances of antibody targeting SpCas9 and SaCas9 found in human serum are as high as 65 and $79 \%$, respectively. This suggests that preexisting anti-Cas9 antibodies in human would most probably impede Cas9 nuclease activity. This important factor must be taken into account as the CRISPR-Cas9 genome editing is making a stride into clinical trials.

\section{Conclusion}

Inheritance of pathogenic germline mutations predisposes carriers to increased risk of developing cancers. Genome editing shows great promise to correct pathogenic mutations. However, biological risks possibly introduced by genome editing platforms are difficult to assess. These include possible toxicity of nucleases delivered into the human cells, undesirable mutation from irreversible genomic changes, gene repair failure that instead results in obtain off-target mutation causative of other diseases and embryo mosaicism (Cornu et al. 2017, Ishii 2017a). Mosaicism in gene-edited embryos is unacceptable in clinical applications, even though studies have shown that mosaic embryos can develop into healthy euploid newborns at significantly lower implantation rates as compared to euploid embryo transfer (Ma et al. 2017, Munné \& Wells 2017, Munné et al. 2017).

The rise of gene editing will be a constant tug-of-war between two forces - private interests/for-profit initiatives and public good - because human germline genome editing is likely to be expensive, limited geographically and might not be covered by all payers and health systems (Ormond et al. 2017). If the main government of a country does not cover the cost of many known inherited genetic disorders, the benefit of disease prevention by germline modification will only be restricted to the wealthier social entities who can afford it, potentially creating social disparities based on market economy (Evitt et al. 2015, Ishii 2017b). Without public funding to support germline editing research, there is a risk that research will go offshore with less oversight and transparency (Ormond et al. 2017).

Notably, the National Institutes of Health just announced \$190 million funding to support Somatic Cell Genome Editing program over 6 years. The focus of this 
program is to dramatically accelerate the translation of these technologies to the clinic for treatment of as many genetic diseases as possible. Clinical trial has started in Europe/United States by CRISPR Therapeutics to treat inherited blood disorder beta thalassemia. With this, we anticipate the day that pathogenic variants will be eliminated from the population as a result of gene drives and mechanistic evolution via gene editing techniques (Esvelt et al. 2014) (Fig. 3E), offering precision medicine in the best interest of patients with hereditary cancers.

\section{Supplementary data}

This is linked to the online version of the paper at https://doi.org/10.1530/ ERC-18-0039.

\section{Declaration of interest}

The authors declare that there is no conflict of interest that could be perceived as prejudicing the impartiality of this review.

\section{Funding}

This work did not receive any specific grant from any funding agency in the public, commercial or not-for-profit sector.

\section{Acknowledgement}

The authors thank Chan Sock Hoai for critical reading of this manuscript.

\section{References}

Abudayyeh OO, Gootenberg JS, Konermann S, Joung J, Slaymaker IM, Cox DBT, Shmakov S, Makarova KS, Semenova E, Minakhin L, et al. 2016 C2c2 is a single-component programmable RNA-guided RNAtargeting CRISPR effector. Science $\mathbf{3 5 3}$ aaf5573. (https://doi. org/10.1126/science.aaf5573)

Abudayyeh OO, Gootenberg JS, Essletzbichler P, Han S, Joung J, Belanto JJ, Verdine V, Cox DBT, Kellner MJ, Regev A, et al. 2017 RNA targeting with CRISPR-Cas13. Nature 550 280-284. (https://doi. org/10.1038/nature24049)

ACMG Board of Directors 2017 Genome editing in clinical genetics: points to consider - a statement of the American College of Medical Genetics and Genomics. Genetics in Medicine 19 723-724. (https:// doi.org/10.1038/gim.2016.195)

Adair JE, Becker PS, Chandrasekaran D, Choi G, Woolfrey AE, Burroughs L \& Kiem H-P 2016a Gene therapy for fanconi anemia in seattle: clinical experience and next steps. Blood 128 3510-3510.

Adair JE, Sevilla J, de Heredia CD, Becker PS, Kiem HP \& Bueren J $2016 b$ Lessons learned from two decades of clinical trial experience in gene therapy for fanconi anemia. Current Gene Therapy 16 338-348. (https://doi.org/10.2174/1566523217666170119113029)

Bagheri-Yarmand R, Sinha KM, Gururaj AE, Ahmed Z, Rizvi YQ, Huang S-C, Ladbury JE, Bogler O, Williams MD, Cote GJ, et al. 2015 A novel dual kinase function of the RET proto-oncogene negatively regulates activating transcription factor 4-mediated apoptosis. Journal of Biological Chemistry 290 11749-11761. (https://doi.org/10.1074/ jbc.M114.619833)
Baltimore D, Berg P, Botchan M, Carroll D, Charo RA, Church G, Corn JE, Daley GQ, Doudna JA, Fenner M, et al. 2015 A prudent path forward for genomic engineering and germline gene modification. Science $\mathbf{3 4 8}$ 36-38. (https://doi.org/10.1126/science.aab1028)

Batra R, Nelles DA, Pirie E, Blue SM, Marina RJ, Wang H, Chaim IA, Thomas JD, Zhang N, Nguyen V, et al. 2017 Elimination of toxic microsatellite repeat expansion RNA by RNA-targeting Cas9. Cell 170 899.e10-912.e10. (https://doi.org/10.1016/j.cell.2017.07.010)

Boch J, Scholze H, Schornack S, Landgraf A, Hahn S, Kay S, Lahaye T, Nickstadt A \& Bonas U 2009 Breaking the code of DNA binding specificity of TAL-type III effectors. Science 326 1509-1512. (https:// doi.org/10.1126/science.1178811)

Bolukbasi MF, Gupta A \& Wolfe SA 2015 Creating and evaluating accurate CRISPR-Cas9 scalpels for genomic surgery. Nature Methods 13 41-50. (https://doi.org/10.1038/nmeth.3684)

Cai L, Fisher AL, Huang H \& Xie Z 2016 CRISPR-mediated genome editing and human diseases. Genes and Diseases 3 244-251. (https:// doi.org/10.1016/j.gendis.2016.07.003)

Capecchi MR 1989 Altering the genome by homologous recombination. Science 244 1288-1292. (https://doi.org/10.1126/science.2660260)

Capps B, Chadwick R, Joly Y, Mulvihill JJ, Lysaght T \& Zwart H 2017 Falling giants and the rise of gene editing: ethics, private interests and the public good. Human Genomics 11 20. (https://doi. org/10.1186/s40246-017-0116-4)

Charlesworth CT, Deshpande PS, Dever DP, Dejene B, Gomez-Ospina N, Mantri S, Pavel-Dinu M, Camarena J, Weinberg KI \& Porteus MH 2018 Identification of pre-existing adaptive immunity to Cas9 proteins in humans. BioRxiv. (https://doi.org/10.1101/243345)

Chen J, Guo Z, Tian H \& Chen X 2016 Production and clinical development of nanoparticles for gene delivery. Molecular Therapy: Methods and Clinical Development 3 16023. (https://doi.org/10.1038/ mtm.2016.23)

Chira S, Gulei D, Hajitou A, Zimta A-A, Cordelier P \& Berindan-Neagoe I 2017 CRISPR/Cas9: transcending the reality of genome editing. Molecular Therapy: Nucleic Acids 7 211-222. (https://doi. org/10.1016/j.omtn.2017.04.001)

Cho SW, Kim S, Kim Y, Kweon J, Kim HS, Bae S \& Kim J-S 2014 Analysis of off-target effects of CRISPR/Cas-derived RNA-guided endonucleases and nickases. Genome Research 24 132-141. (https://doi.org/10.1101/ gr.162339.113)

Cong L, Ran FA, Cox D, Lin S, Barretto R, Habib N, Hsu PD, Wu X, Jiang W, Marraffini LA, et al. 2013 Multiplex genome engineering using CRISPR/Cas systems. Science 339 819-823. (https://doi. org/10.1126/science.1231143)

Cornu TI, Mussolino C \& Cathomen T 2017 Refining strategies to translate genome editing to the clinic. Nature Medicine 23 415-423. (https://doi.org/10.1038/nm.4313)

Cox DBT, Gootenberg JS, Abudayyeh OO, Franklin B, Kellner MJ, Joung J \& Zhang F 2017 RNA editing with CRISPR-Cas13. Science 358 1019-1027. (https://doi.org/10.1126/science.aaq0180)

Dahlman JE, Abudayyeh OO, Joung J, Gootenberg JS, Zhang F \& Konermann S 2015 Orthogonal gene knockout and activation with a catalytically active Cas9 nuclease. Nature Biotechnology 33 1159-1161. (https://doi.org/10.1038/nbt.3390)

Davis KM, Pattanayak V, Thompson DB, Zuris JA \& Liu DR 2015 Small molecule-triggered Cas9 protein with improved genome-editing specificity. Nature Chemical Biology 11 316-318. (https://doi. org/10.1038/nchembio.1793)

Daya S \& Berns KI 2008 Gene therapy using adeno-associated virus vectors. Clinical Microbiology Reviews 21 583-593. (https://doi. org/10.1128/CMR.00008-08)

de Solis CA, Ho A, Holehonnur R \& Ploski JE 2016 The development of a viral mediated CRISPR/Cas9 system with doxycycline dependent gRNA expression for inducible in vitro and in vivo genome editing. Frontiers in Molecular Neuroscience 9. (https://doi.org/10.3389/ fnmol.2016.00070)
(C) 2018 Society for Endocrinology Published by Bioscientifica Ltd. Printed in Great Britain 
de Wert G, Pennings G, Clarke A, Eichenlaub-Ritter U, van El CG, Forzano F, Goddijn M, Heindryckx B, Howard HC, Radojkovic D, et al. 2018 Human germline gene editing: recommendations of ESHG and ESHRE. European Journal of Human Genetics 26 445-449. (https://doi.org/10.1038/s41431-017-0076-0)

Doudna JA 2014 Use of CRISPR/Cas9, ZFNs, and TALENs in Generating Site-Specific Genome Alterations. Amsterdam, Netherlands: Elsevier, Academic Press.

Doudna JA \& Sternberg SH 2017 A Crack in Creation: Gene Editing and the Unthinkable Power to Control Evolution. Boston, MA, USA: Houghton Mifflin Harcourt.

Dykman LA \& Khlebtsov NG 2017 Immunological properties of gold nanoparticles. Chemical Science 8 1719-1735. (https://doi. org/10.1039/C6SC03631G)

East-Seletsky A, O'Connell MR, Knight SC, Burstein D, Cate JHD, Tjian R \& Doudna JA 2016 Two distinct RNase activities of CRISPR-C2c2 enable guide-RNA processing and RNA detection. Nature $\mathbf{5 3 8}$ 270-273. (https://doi.org/10.1038/nature19802)

East-Seletsky A, O'Connell MR, Burstein D, Knott GJ \& Doudna JA 2017 RNA targeting by functionally orthogonal type VI-A CRISPR-Cas enzymes. Molecular Cell 66 373.e3-383.e3. (https://doi.org/10.1016/j. molcel.2017.04.008)

Ebens CL, MacMillan ML \& Wagner JE 2017 Hematopoietic cell transplantation in Fanconi anemia: current evidence, challenges and recommendations. Expert Review of Hematology 10 81-97. (https:// doi.org/10.1080/17474086.2016.1268048)

Esvelt KM, Smidler AL, Catteruccia F \& Church GM 2014 Emerging technology: concerning RNA-guided gene drives for the alteration of wild populations. eLife 3 e03401. (https://doi.org/10.7554/ eLife.03401)

Evitt NH, Mascharak S \& Altman RB 2015 Human germline CRISPR-Cas modification: toward a regulatory framework. American Journal of Bioethics 15 25-29. (https://doi.org/10.1080/15265161.2015.1104160)

Fu Y, Foden JA, Khayter C, Maeder ML, Reyon D, Joung JK \& Sander JD 2013 High frequency off-target mutagenesis induced by CRISPR-Cas nucleases in human cells. Nature Biotechnology 31 822-826. (https:// doi.org/10.1038/nbt.2623)

Fu Y, Sander JD, Reyon D, Cascio VM \& Joung JK 2014 Improving CRISPR-Cas nuclease specificity using truncated guide RNAs. Nature Biotechnology 32 279-284. (https://doi.org/10.1038/nbt.2808)

Garber JE \& Offit K 2005 Hereditary cancer predisposition syndromes. Journal of Clinical Oncology 23 276-292. (https://doi.org/10.1200/ JCO.2005.10.042)

Gasiunas G, Barrangou R, Horvath P \& Siksnys V 2012 Cas9-crRNA ribonucleoprotein complex mediates specific DNA cleavage for adaptive immunity in bacteria. PNAS 109 E2579-E2586. (https://doi. org/10.1073/pnas.1208507109)

Gaudelli NM, Komor AC, Rees HA, Packer MS, Badran AH, Bryson DI \& Liu DR 2017 Programmable base editing of $A \bullet T$ to $\mathrm{G} \bullet \mathrm{C}$ in genomic DNA without DNA cleavage. Nature 551 464-471. (https://doi. org/10.1038/nature24644)

Gazdar A, Robinson L, Oliver D, Xing C, Travis WD, Soh J, Toyooka S, Watumull L, Xie Y, Kernstine K, et al. 2014 Hereditary lung cancer syndrome targets never smokers with germline EGFR gene T790M mutations. Journal of Thoracic Oncology 9 456-463. (https://doi. org/10.1097/JTO.0000000000000130)

Gootenberg JS, Abudayyeh OO, Lee JW, Essletzbichler P, Dy AJ, Joung J, Verdine V, Donghia N, Daringer NM, Freije CA, et al. 2017 Nucleic acid detection with CRISPR-Cas13a/C2c2. Science 356 438-442. (https://doi.org/10.1126/science.aam9321)

Götherström C, Westgren M, Shaw SWS, Åström E, Biswas A, Byers PH, Mattar CNZ, Graham GE, Taslimi J, Ewald U, et al. 2014 Pre- and postnatal transplantation of fetal mesenchymal stem cells in osteogenesis imperfecta: a two-center experience. Stem Cells Translational Medicine 3 255-264. (https://doi.org/10.5966/sctm.20130090)
Guha TK, Wai A \& Hausner G 2017 Programmable genome editing tools and their regulation for efficient genome engineering. Computational and Structural Biotechnology Journal 15 146-160. (https://doi. org/10.1016/j.csbj.2016.12.006)

Guilinger JP, Thompson DB \& Liu DR 2014 Fusion of catalytically inactive Cas 9 to FokI nuclease improves the specificity of genome modification. Nature Biotechnology 32 577-582. (https://doi. org/10.1038/nbt.2909)

Hill VK, Kim J-S, James CD \& Waldman T 2017 Correction of PTEN mutations in glioblastoma cell lines via AAV-mediated gene editing. PLoS ONE 12 e0176683. (https://doi.org/10.1371/journal. pone.0176683)

Hirsch T, Rothoeft T, Teig N, Bauer JW, Pellegrini G, De Rosa L, Scaglione D, Reichelt J, Klausegger A, Kneisz D, et al. 2017 Regeneration of the entire human epidermis using transgenic stem cells. Nature 551 327. (https://doi.org/10.1038/nature24487)

Hodgson S 2008 Mechanisms of inherited cancer susceptibility. Journal of Zhejiang University Science B 9 1-4. (https://doi.org/10.1631/jzus. B073001)

Howard HC, van El CG, Forzano F, Radojkovic D, Rial-Sebbag E, de Wert G, Borry P \& Cornel MC 2018 One small edit for humans, one giant edit for humankind? Points and questions to consider for a responsible way forward for gene editing in humans. European Journal of Human Genetics 26 1-11. (https://doi.org/10.1038/s41431017-0024-z)

Hsu PD, Lander ES \& Zhang F 2014 Development and applications of CRISPR-Cas9 for genome engineering. Cell 157 1262-1278. (https:// doi.org/10.1016/j.cell.2014.05.010)

Huang BY, Zhan YP, Zong WJ, Yu CJ, Li JF, Qu YM \& Han S 2015 The PD-1/B7-H1 pathway modulates the natural killer cells versus mouse glioma stem cells. PLoS One 10 e0134715. (https://doi.org/10.1371/ journal.pone.0134715)

Huch M, Dorrell C, Boj SF, van Es JH, Li VSW, van de Wetering M, Sato T, Hamer K, Sasaki N, Finegold MJ, et al. 2013 In vitro expansion of single Lgr5+ liver stem cells induced by Wnt-driven regeneration. Nature 494 247. (https://doi.org/10.1038/nature11826)

Ishii T 2017a Reproductive medicine involving genome editing: clinical uncertainties and embryological needs. Reproductive BioMedicine Online 34 27-31. (https://doi.org/10.1016/j.rbmo.2016.09.009)

Ishii T $2017 b$ Germ line genome editing in clinics: the approaches, objectives and global society. Briefings in Functional Genomics 16 46-56. (https://doi.org/10.1093/bfgp/elv053)

Ishino Y, Shinagawa H, Makino K, Amemura M \& Nakata A 1987 Nucleotide sequence of the iap gene, responsible for alkaline phosphatase isozyme conversion in Escherichia coli, and identification of the gene product. Journal of Bacteriology 169 5429-5433. (https://doi.org/10.1128/jb.169.12.5429-5433.1987)

Jiang F \& Doudna JA 2017 CRISPR-Cas9 structures and mechanisms. Annual Review of Biophysics 46 505-529. (https://doi.org/10.1146/ annurev-biophys-062215-010822)

Jin S, Leach JC \& Ye K 2009 Nanoparticle-mediated gene delivery. In Micro and Nano Technologies in Bioanalysis, pp 547-557. Totowa, NJ, USA: Humana Press. (https://doi.org/10.1007/978-1-59745-483-4_34)

Jinek M, Chylinski K, Fonfara I, Hauer M, Doudna JA \& Charpentier E 2012 A programmable dual-RNA-guided DNA endonuclease in adaptive bacterial immunity. Science 337 816-821. (https://doi. org/10.1126/science.1225829)

Jung C, Hawkins JA, Jones SK, Xiao Y, Rybarski JR, Dillard KE, Hussmann J, Saifuddin FA, Savran CA, Ellington AD, et al. 2017 Massively parallel biophysical analysis of CRISPR-Cas complexes on next generation sequencing chips. Cell 170 35.e13-47.e13. (https:// doi.org/10.1016/j.cell.2017.05.044)

Jyonouchi S, Abraham V, Orange JS, Spergel JM, Gober L, Dudek E, Saltzman R, Nichols KE \& Cianferoni A 2011 Invariant natural killer $\mathrm{T}$ cells from food allergic versus non-allergic children exhibit differential responsiveness to milk-derived sphingomyelin. Journal of 
Allergy and Clinical Immunology 128 102-109.e113. (https://doi. org/10.1016/j.jaci.2011.02.026)

Kim YG, Cha J \& Chandrasegaran S 1996 Hybrid restriction enzymes: zinc finger fusions to Fok I cleavage domain. PNAS 93 1156-1160. (https://doi.org/10.1073/pnas.93.3.1156)

Komor AC, Kim YB, Packer MS, Zuris JA \& Liu DR 2016 Programmable editing of a target base in genomic DNA without double-stranded DNA cleavage. Nature 533 420-424. (https://doi.org/10.1038/ nature17946)

Komor AC, Zhao KT, Packer MS, Gaudelli NM, Waterbury AL, Koblan LW, Kim YB, Badran AH \& Liu DR 2017a Improved base excision repair inhibition and bacteriophage Mu Gam protein yields C:G-to-T:A base editors with higher efficiency and product purity. Science Advances 3 eaao4774. (https://doi.org/10.1126/sciadv. aao4774)

Komor AC, Badran AH \& Liu DR 2017b Editing the genome without double-stranded DNA breaks. ACS Chemical Biology 13 383-388. (https://doi.org/10.1021/acschembio.7b00710)

Koo T, Yoon A-R, Cho H-Y, Bae S, Yun C-O \& Kim J-S 2017 Selective disruption of an oncogenic mutant allele by CRISPR/Cas9 induces efficient tumor regression. Nucleic Acids Research 45 7897-7908. (https://doi.org/10.1093/nar/gkx490)

Lander ES 2016 The heroes of CRISPR. Cell 164 18-28. (https://doi. org/10.1016/j.cell.2015.12.041)

Lanphier E \& Urnov F 2015 Don't edit the human germ line. Nature 519 410. (https://doi.org/10.1038/519410a)

Lee K, Conboy M, Park HM, Jiang F, Kim HJ, Dewitt MA, Mackley VA, Chang K, Rao A, Skinner C, et al. 2017 Nanoparticle delivery of Cas9 ribonucleoprotein and donor DNA in vivo induces homologydirected DNA repair. Nature Biomedical Engineering 1 889-901. (https://doi.org/10.1038/s41551-017-0137-2)

Li T, Huang S, Jiang WZ, Wright D, Spalding MH, Weeks DP \& Yang B 2011 TAL nucleases (TALNs): hybrid proteins composed of TAL effectors and FokI DNA-cleavage domain. Nucleic Acids Research 39 359-372. (https://doi.org/10.1093/nar/gkq704)

Liang P, Ding C, Sun H, Xie X, Xu Y, Zhang X, Sun Y, Xiong Y, Ma W, Liu Y, et al. 2017 Correction of $\beta$-thalassemia mutant by base editor in human embryos. Protein and Cell 8 811-822. (https://doi. org/10.1007/s13238-017-0475-6)

Liao H-K, Hatanaka F, Araoka T, Reddy P, Wu M-Z, Sui Y, Yamauchi T, Sakurai M, O'Keefe DD, Núñez-Delicado E, et al. 2017 In vivo target gene activation via CRISPR/Cas9-mediated trans-epigenetic modulation. Cell 171 1495.e15-1507.e15. (https://doi.org/10.1016/j. cell.2017.10.025)

Liu G-H, Suzuki K, Li M, Qu J, Montserrat N, Tarantino C, Gu Y, Yi F, $\mathrm{Xu}$ X, Zhang W, et al. 2014a Modeling Fanconi Anemia pathogenesis and therapeutics using integration-free patient-derived iPSCs. Nature Communications 5 4330. (https://doi.org/10.1038/ncomms5330)

Liu J, Gaj T, Patterson JT, Sirk SJ \& Barbas CF III 2014b Cell-penetrating peptide-mediated delivery of TALEN proteins via bioconjugation for genome engineering. PLOS ONE 9 e85755. (https://doi.org/10.1371/ journal.pone.0085755)

Liu H, Zeng F, Zhang M, Huang F, Wang J, Guo J, Liu C \& Wang H 2016 Emerging landscape of cell penetrating peptide in reprogramming and gene editing. Journal of Controlled Release 226 124-137. (https:// doi.org/10.1016/j.jconrel.2016.02.002)

Liu L, Li X, Ma J, Li Z, You L, Wang J, Wang M, Zhang X \& Wang Y 2017 The molecular architecture for RNA-guided RNA cleavage by Cas13a. Cell 170 714.e10-726.e10. (https://doi.org/10.1016/j. cell.2017.06.050)

Liu P, Chen M, Liu Y, Qi LS \& Ding S 2018 CRISPR-based chromatin remodeling of the endogenous Oct4 or Sox 2 locus enables reprogramming to pluripotency. Cell Stem Cell 22 252.e4-261.e4. (https://doi.org/10.1016/j.stem.2017.12.001)

Ma H, Marti-Gutierrez N, Park S-W, Wu J, Lee Y, Suzuki K, Koski A, Ji D, Hayama T, Ahmed R, et al. 2017 Correction of a pathogenic gene mutation in human embryos. Nature 548 413-419. (https://doi. org/10.1038/nature23305)

Makarova KS, Zhang F \& Koonin EV 2017 Snapshot: class 2 CRISPR-Cas systems. Cell 168 328-328. (https://doi.org/10.1016/j. cell.2016.12.038)

Mali P, Aach J, Stranges PB, Esvelt KM, Moosburner M, Kosuri S, Yang L \& Church GM 2013 CAS9 transcriptional activators for target specificity screening and paired nickases for cooperative genome engineering. Nature Biotechnology 31 833-838. (https://doi. org/10.1038/nbt.2675)

Miller JC, Holmes MC, Wang J, Guschin DY, Lee Y-L, Rupniewski I, Beausejour CM, Waite AJ, Wang NS, Kim KA, et al. 2007 An improved zinc-finger nuclease architecture for highly specific genome editing. Nature Biotechnology 25 778-785. (https://doi. org/10.1038/nbt1319)

Miller JC, Tan S, Qiao G, Barlow KA, Wang J, Xia DF, Meng X, Paschon DE, Leung E, Hinkley SJ, et al. 2011 A TALE nuclease architecture for efficient genome editing. Nature Biotechnology 29 143-148. (https://doi.org/10.1038/nbt.1755)

Munné S \& Wells D 2017 Detection of mosaicism at blastocyst stage with the use of high-resolution next-generation sequencing. Fertility and Sterility 107 1085-1091. (https://doi.org/10.1016/j. fertnstert.2017.03.024)

Munné S, Blazek J, Large M, Martinez-Ortiz PA, Nisson H, Liu E, Tarozzi N, Borini A, Becker A, Zhang J, et al. 2017 Detailed investigation into the cytogenetic constitution and pregnancy outcome of replacing mosaic blastocysts detected with the use of high-resolution next-generation sequencing. Fertility and Sterility 108 62.e8-71.e8. (https://doi.org/10.1016/j.fertnstert.2017.05.002)

Myers KC, Bleesing JJ, Davies SM, Zhang X, Martin LJ, Mueller R, Harris RE, Filipovich AH, Kovacic MB, Wells SI, et al. 2011 Impaired immune function in children with Fanconi anaemia. British Journal of Haematology 154 234-240. (https://doi. org/10.1111/j.1365-2141.2011.08721.x)

Nakade S, Yamamoto T \& Sakuma T 2017 Cas9, Cpf1 and C2c1/2/3 what's next? Bioengineered 8 265-273. (https://doi.org/10.1080/21655 979.2017.1282018)

Navarro S, Giorgetti A, Raya A \& Tolar J 2016 Induced pluripotency and gene editing in fanconi anemia. Current Gene Therapy 16 321-328. (https://doi.org/10.2174/1566523217666170118112050)

Nelles DA, Fang MY, Aigner S \& Yeo GW 2015 Applications of Cas9 as an RNA-programmed RNA-binding protein. BioEssays 37 732-739. (https://doi.org/10.1002/bies.201500001)

Nelles DA, Fang MY, O'Connell MR, Xu JL, Markmiller SJ, Doudna JA \& Yeo GW 2016 Programmable RNA tracking in live cells with CRISPR/Cas9. Cell 165 488-496. (https://doi.org/10.1016/j. cell.2016.02.054)

Nishida K, Arazoe T, Yachie N, Banno S, Kakimoto M, Tabata M, Mochizuki M, Miyabe A, Araki M, Hara KY, et al. 2016 Targeted nucleotide editing using hybrid prokaryotic and vertebrate adaptive immune systems. Science $\mathbf{3 5 3}$ aaf8729. (https://doi.org/10.1126/ science.aaf8729)

Nishimasu H, Ran FA, Hsu PD, Konermann S, Shehata S, Dohmae N, Ishitani R, Zhang F \& Nureki O 2014 Crystal structure of Cas9 in complex with guide RNA and target DNA. Cell 156 935-949. (https://doi.org/10.1016/j.cell.2014.02.001)

O'Connell MR, Oakes BL, Sternberg SH, East-Seletsky A, Kaplan M \& Doudna JA 2014 Programmable RNA recognition and cleavage by CRISPR/Cas9. Nature 516 263-266. (https://doi.org/10.1038/ nature13769)

Ormond KE, Mortlock DP, Scholes DT, Bombard Y, Brody LC, Faucett WA, Garrison NA, Hercher L, Isasi R, Middleton A, et al. 2017 Human germline genome editing. American Journal of Human Genetics 101 167-176. (https://doi.org/10.1016/j.ajhg.2017.06.012)

Osborn MJ, Gabriel R, Webber BR, DeFeo AP, McElroy AN, Jarjour J, Starker CG, Wagner JE, Joung JK, Voytas DF, et al. 2015 Fanconi
(2) 2018 Society for Endocrinology Published by Bioscientifica Ltd. Printed in Great Britain 
anemia gene editing by the CRISPR/Cas9 system. Human Gene Therapy 26 114-126. (https://doi.org/10.1089/hum.2014.111)

Osborn MJ, Lonetree C, Webber BR, Patel D, Dunmire S, DeFeo AP, McElroy AN, MacMillan ML, Wagner JE, Blazar BR, et al. 2016 CRISPR/Cas9 targeted gene editing and cellular engineering in fanconi anemia. Stem Cells and Development 25 1591-1603. (https:// doi.org/10.1089/scd.2016.0149)

Pattanayak V, Lin S, Guilinger JP, Ma E, Doudna JA \& Liu DR 2013 Highthroughput profiling of off-target DNA cleavage reveals RNAprogrammed Cas9 nuclease specificity. Nature Biotechnology $\mathbf{3 1}$ 839-843. (https://doi.org/10.1038/nbt.2673)

Rahman N 2014 Realizing the promise of cancer predisposition genes. Nature 505 302-308. (https://doi.org/10.1038/nature12981)

Ramakrishna S, Dad A-BK, Beloor J, Gopalappa R, Lee S-K \& Kim H 2014 Gene disruption by cell-penetrating peptide-mediated delivery of Cas9 protein and guide RNA. Genome Research 24 1020-1027. (https://doi.org/10.1101/gr.171264.113)

Ramirez CL, Certo MT, Mussolino C, Goodwin MJ, Cradick TJ, McCaffrey AP, Cathomen T, Scharenberg AM \& Joung JK 2012 Engineered zinc finger nickases induce homology-directed repair with reduced mutagenic effects. Nucleic Acids Research 40 5560-5568. (https://doi.org/10.1093/nar/gks179)

Ran FA, Hsu PD, Lin C-Y, Gootenberg JS, Konermann S, Trevino A, Scott DA, Inoue A, Matoba S, Zhang Y, et al. 2013 Double nicking by RNA-guided CRISPR Cas9 for enhanced genome editing specificity. Cell 154 1380-1389. (https://doi.org/10.1016/j.cell.2013.08.021)

Raya Á, Rodríguez-Pizà I, Guenechea G, Vassena R, Navarro S, Barrero MJ, Consiglio A, Castellà M, Río P, Sleep E, et al. 2009 Disease-corrected haematopoietic progenitors from Fanconi anaemia induced pluripotent stem cells. Nature 460 53-59. (https://doi. org/10.1038/nature08129)

Richards S, Aziz N, Bale S, Bick D, Das S, Gastier-Foster J, Grody WW, Hegde M, Lyon E, Spector E, et al. 2015 Standards and guidelines for the interpretation of sequence variants: a joint consensus recommendation of the American College of Medical Genetics and Genomics and the Association for Molecular Pathology. Genetics in Medicine 17 405-423. (https://doi.org/10.1038/gim.2015.30)

Rio P, Baños R, Lombardo A, Quintana-Bustamante O, Alvarez L, Garate Z, Genovese P, Almarza E, Valeri A, Díez B, et al. 2014 Targeted gene therapy and cell reprogramming in Fanconi anemia. EMBO Molecular Medicine 6 835-848. (https://doi.org/10.15252/ emmm.201303374)

Sagar R, Walther-Jallow L, David AL, Götherström C \& Westgren M 2018 Fetal mesenchymal stromal cells: an opportunity for prenatal cellular therapy. Current Stem Cell Reports 4 61-68. (https://doi.org/10.1007/ s40778-018-0118-8)

Sander JD \& Joung JK 2014 CRISPR-Cas systems for editing, regulating and targeting genomes. Nature Biotechnology 32 347-355. (https:// doi.org/10.1038/nbt.2842)

Schwank G, Koo B-K, Sasselli V, Dekkers Johanna F, Heo I, Demircan T, Sasaki N, Boymans S, Cuppen E, van der Ent Cornelis K, et al. 2013 Functional repair of CFTR by CRISPR/Cas9 in intestinal stem cell organoids of cystic fibrosis patients. Cell Stem Cell 13 653-658. (https://doi.org/10.1016/j.stem.2013.11.002)

Shmakov S, Smargon A, Scott D, Cox D, Pyzocha N, Yan W, Abudayyeh OO, Gootenberg JS, Makarova KS, Wolf YI, et al. 2017 Diversity and evolution of class 2 CRISPR-Cas systems. Nature Reviews Microbiology 15 169-182. (https://doi.org/10.1038/ nrmicro.2016.184)

Shukla P, Ghosh K \& Vundinti BR 2012 Current and emerging therapeutic strategies for Fanconi anemia. HUGO Journal 61. (https://doi.org/10.1186/1877-6566-6-1)

Skvarova Kramarzova K, Osborn M, Webber B, DeFeo A, McElroy A, Kim C \& Tolar J 2017 CRISPR/Cas9-mediated correction of the FANCD1 gene in primary patient cells. International Journal of Molecular Sciences 18 1269. (https://doi.org/10.3390/ijms18061269)
Smargon AA, Cox DBT, Pyzocha NK, Zheng K, Slaymaker IM, Gootenberg JS, Abudayyeh OA, Essletzbichler P, Shmakov S, Makarova KS, et al. 2017 Cas13b is a type VI-B CRISPR-associated RNA-guided RNAse differentially regulated by accessory proteins Csx27 and Csx28. Molecular Cell 65 618.e7-630.e7. (https://doi. org/10.1016/j.molcel.2016.12.023)

Starink TM, van der Veen JPW, Arwert F, de Waal LP, de Lange GG, Gille JJP \& Eriksson AW 1986 The Cowden syndrome: a clinical and genetic study in 21 patients. Clinical Genetics 29 222-233. (https:// doi.org/doi:10.1111/j.1399-0004.1986.tb00816.x)

Sternberg SH, LaFrance B, Kaplan M \& Doudna JA 2015 Conformational control of DNA target cleavage by CRISPR-Cas9. Nature $\mathbf{5 2 7}$ 110-113. (https://doi.org/10.1038/nature15544)

Sugimura R, Jha DK, Han A, Soria-Valles C, da Rocha EL, Lu Y-F Goettel JA, Serrao E, Rowe RG, Malleshaiah M, et al. 2017 Haematopoietic stem and progenitor cells from human pluripotent stem cells. Nature 545 432-438. (https://doi.org/10.1038/ nature22370)

Suresh B, Ramakrishna S \& Kim H 2017 Cell-penetrating peptidemediated delivery of Cas9 protein and guide RNA for genome editing. In Eukaryotic Transcriptional and Post-Transcriptional Gene Expression Regulation, pp 81-94. New York, NY, USA: Humana Press. (https://doi.org/10.1007/978-1-4939-6518-2_7)

Takata M, Sasaki MS, Sonoda E, Morrison C, Hashimoto M, Utsumi H, Yamaguchi-Iwai Y, Shinohara A \& Takeda S 1998 Homologous recombination and non-homologous end-joining pathways of DNA double-strand break repair have overlapping roles in the maintenance of chromosomal integrity in vertebrate cells. EMBO Journal 17 5497-5508. (https://doi.org/10.1093/ emboj/17.18.5497)

Tasan I \& Zhao H 2017 Targeting specificity of the CRISPR/Cas9 system. ACS Synthetic Biology 6 1609-1613. (https://doi.org/10.1021/ acssynbio.7b00270)

Tsai SQ \& Joung JK 2016 Defining and improving the genome-wide specificities of CRISPR-Cas9 nucleases. Nature Reviews Genetics 17 300-312. (https://doi.org/10.1038/nrg.2016.28)

Tsai SQ, Wyvekens N, Khayter C, Foden JA, Thapar V, Reyon D, Goodwin MJ, Aryee MJ \& Joung JK 2014 Dimeric CRISPR RNAguided FokI nucleases for highly specific genome editing. Nature Biotechnology 32 569-576. (https://doi.org/10.1038/nbt.2908)

Vassena R, Heindryckx B, Peco R, Pennings G, Raya A, Sermon K \& Veiga A 2016 Genome engineering through CRISPR/Cas9 technology in the human germline and pluripotent stem cells. Human Reproduction Update 22 411-419. (https://doi.org/10.1093/humupd/ dmw005)

Vogelstein B \& Kinzler KW 2004 Cancer genes and the pathways they control. Nature Medicine 10 789-799. (https://doi.org/10.1038/ $\mathrm{nm} 1087)$

Xie K, Minkenberg B \& Yang Y 2015 Boosting CRISPR/Cas9 multiplex editing capability with the endogenous tRNA-processing system. PNAS 112 3570-3575. (https://doi.org/10.1073/pnas.1420294112)

Yang L, Briggs AW, Chew WL, Mali P, Guell M, Aach J, Goodman DB, Cox D, Kan Y, Lesha E, et al. 2016 Engineering and optimising deaminase fusions for genome editing. Nature Communications 7 13330. (https://doi.org/10.1038/ncomms13330)

Yin X, Mead BE, Safaee H, Langer R, Karp JM \& Levy O 2016 Engineering stem cell organoids. Cell Stem Cell 18 25-38. (https:// doi.org/10.1016/j.stem.2015.12.005)

Yin H, Kauffman KJ \& Anderson DG 2017 Delivery technologies for genome editing. Nature Reviews Drug Discovery 16 387-399. (https:// doi.org/10.1038/nrd.2016.280)

Yui S, Nakamura T, Sato T, Nemoto Y, Mizutani T, Zheng X, Ichinose S, Nagaishi T, Okamoto R, Tsuchiya K, et al. 2012 Functional engraftment of colon epithelium expanded in vitro from a single adult Lgr5+ stem cell. Nature Medicine 18 618. (https://doi. org/10.1038/nm.2695)
C 2018 Society for Endocrinology Published by Bioscientifica Ltd. Printed in Great Britain 
Zetsche B, Gootenberg JS, Abudayyeh OO, Slaymaker IM, Makarova KS, Essletzbichler P, Volz S, Joung J, van der Oost J, Regev A, et al. 2015 Cpf1 is a single RNA-guided endonuclease of a Class 2 CRISPR-Cas system. Cell 163 759-771. (https://doi.org/10.1016/j.cell.2015.09.038)

Zetsche B, Heidenreich M, Mohanraju P, Fedorova I, Kneppers J, DeGennaro EM, Winblad N, Choudhury SR, Abudayyeh OO, Gootenberg JS, et al. 2016 Multiplex gene editing by CRISPR-Cpf1 using a single crRNA array. Nature Biotechnology 35 31-34. (https:// doi.org/10.1038/nbt.3737)

Zhang X-H, Tee LY, Wang X-G, Huang Q-S \& Yang S-H 2015 Off-target effects in CRISPR/Cas9-mediated genome engineering. Molecular
Therapy: Nucleic Acids 4 e264. (https://doi.org/10.1038/ mtna.2015.37)

Zhou H, Liu J, Zhou C, Gao N, Rao Z, Li H, Hu X, Li C, Yao X, Shen X, et al. 2018 In vivo simultaneous transcriptional activation of multiple genes in the brain using CRISPR-dCas9-activator transgenic mice. Nature Neuroscience 21 440-446. (https://doi.org/10.1038/ s41593-017-0060-6)

Zuris JA, Thompson DB, Shu Y, Guilinger JP, Bessen JL, Hu JH, Maeder ML, Joung JK, Chen Z-Y \& Liu DR 2015 Efficient delivery of genome-editing proteins in vitro and in vivo. Nature Biotechnology 33 73-80. (https://doi.org/10.1038/nbt.3081)

Received in final form 8 May 2018

Accepted 10 May 2018 (c) 2018 Society for Endocrinology Published by Bioscientifica Ltd. 